\title{
Mast Cells and Fibroblasts Work in Concert to Aggravate Pulmonary Fibrosis
}

\section{Role of Transmembrane SCF and the PAR-2/PKC- $\alpha /$ Raf-1/ p44/42 Signaling Pathway}

Malgorzata Wygrecka, ${ }^{* \dagger}$ Bhola K. Dahal, ${ }^{\ddagger}$ Djuro Kosanovic, ${ }^{\ddagger}$ Frank Petersen, ${ }^{\dagger \S}$ Brigitte Taborski, ${ }^{*}$ Susanne von Gerlach, ${ }^{\natural}$ Miroslava Didiasova, ${ }^{*}$ Dariusz Zakrzewicz, ${ }^{*}$ Klaus T. Preissner, ${ }^{\star \dagger}$ Ralph T. Schermuly, ${ }^{\dagger \ddagger}$ and Philipp Markart ${ }^{\dagger \ddagger}$

From the Departments of Biochemistry, * Internal Medicine, ${ }^{\ddagger}$ and Pathology, ${ }^{\top}$ Justus-Liebig-University Giessen, Universities Giessen and Marburg Lung Center, ${ }^{\dagger}$ and the German Center for Lung Research (DZL), Giessen; and the Section for Immunoregulation, ${ }^{\S}$ Research Center Borstel, Borstel, Germany

Accepted for publication

February 4, 2013.

Address correspondence to Malgorzata Wygrecka, Ph.D., Department of Biochemistry, Faculty of Medicine, University of Giessen Lung Center, Friedrichstrasse 24, 35392 Giessen, Germany. E-mail: malgorzata. wygrecka@innere.med.unigiessen.de.

\begin{abstract}
Mast cell (MC) accumulation has been demonstrated in the lungs of idiopathic pulmonary fibrosis (IPF) patients. Mediators released from MCs may regulate tissue remodeling processes, thereby contributing to IPF pathogenesis. We investigated the role of $M C$-fibroblast interaction in the progression of lung fibrosis. Increased numbers of activated MCs, in close proximity to fibroblast foci and alveolar type II cells, were observed in IPF lungs. Correspondingly elevated tryptase levels were detected in IPF lung tissue samples. Coculture of human lung MCs with human lung fibroblasts (HLFs) induced MC activation, as evinced by tryptase release, and stimulated HLF proliferation; IPF HLFs exhibited a significantly higher growth rate, compared with control. Tryptase stimulated HLF growth in a PAR-2/PKC- $\alpha /$ Raf-1/p44/42-dependent manner and potentiated extracellular matrix production, but independent of PKC- $\alpha$, Raf-1, and p44/42 activities. Proproliferative properties of tryptase were attenuated by knockdown or pharmacological inhibition of PAR-2, PKC- $\alpha$, Raf- 1 , or p44/42. Expression of transmembrane SCF, but not soluble SCF, was elevated in IPF lung tissue and in fibroblasts isolated from IPF lungs. Coculture of IPF HLFs with MCs enhanced MC survival and proliferation. These effects were cell-contact dependent and could be inhibited by application of anti-SCF antibody or CD117 inhibitor. Thus, fibroblasts and MCs appear to work in concert to perpetuate fibrotic processes and so contribute to lung fibrosis progression. (Am J Pathol 2013, 182: 2094-2108; http://dx.doi.org/10.1016/j.ajpath.2013.02.013)
\end{abstract}

Mast cells (MCs) originate from CD34-expressing hematopoietic stem cells in the bone marrow. They circulate in the blood as monocyte-like precursors and then home to tissues, where they mature under the influence of stem cell factor (SCF) and local cytokines. ${ }^{1}$ MCs are predominantly localized at sites that have direct contact with the external environment, such as the skin, airways, and intestine, where they function as sentinel cells in host defense. ${ }^{2}$ Upon activation, MCs release their granule contents, which include proteases (tryptase, chymase, carboxypeptidase), vasoactive amines (histamine, serotonin), proteoglycans (heparin, chondroitin sulfate), and growth factors [transforming growth factor- $\beta 1$
(TGF- $\beta 1$ ), vascular endothelial growth factor (VEGF), basic fibroblast growth factor (bFGF)]. ${ }^{3}$ In addition, activated MCs are able to produce a variety of cytokines [IL-1 $\alpha$, IL-6, granulocyte-monocyte colony-stimulating factor (GMCSF), interferon- $\alpha$ (IFN- $\alpha$ )], chemokines (CCL-2, CCL-5, CXCL-1), and lipid mediators [leukotriene C4 ( $\left.\mathrm{LTC}_{4}\right)$, $\mathrm{LTB}_{4}$, prostaglandin $\left.2\left(\mathrm{PGE}_{2}\right)\right]^{3}$ The broad spectrum of

Supported by the Excellence Cluster "Cardiopulmonary System" (ECCPS) (M.W. and D.Z.), University Medical Center Giessen and Marburg (UKGM) (M.W. and P.M.), German Research Foundation (DFG; WY 119/1-1, SFB/TR84) (M.W. and K.T.P.). 
molecules produced by MCs might explain their varied functions: the recruitment, activation, and differentiation of inflammatory cells ${ }^{4-6}$ and the regulation of vascular permeability, ${ }^{2}$ smooth-muscle cell contractility, ${ }^{7}$ and fibroblast growth. ${ }^{8}$ Thus, MCs have been found to be involved in the pathogenesis of allergic, chronic inflammatory, and fibrotic diseases.

An association between MC infiltration and the degree of fibrosis has been found in various kidney disorders, including focal segmental glomerulosclerosis, IgA nephropathy, renal amyloidosis, and lupus nephritis, ${ }^{9-11}$ as well as in liver cirrhosis ${ }^{12}$ and in the minor salivary glands of patients with Sjögren's syndrome. ${ }^{13}$ In addition, a growing body of evidence suggests that MCs may play a role in the pathogenesis of fibrotic lung diseases. Elevated numbers of MCs were found in the lungs of patients with sarcoidosis, ${ }^{14}$ cryptogenic organizing pneumonia, ${ }^{15}$ hypersensitivity pneumonitis, ${ }^{15}$ silicosis, ${ }^{16}$ and idiopathic pulmonary fibrosis (IPF). ${ }^{17-19}$ Moreover, increased levels of tryptase were measured in bronchoalveolar lavage fluid (BALF) from IPF patients, and tryptase-positive IPF cases were reported to have a poorer outcome. ${ }^{20}$ The possible involvement of MCs in the pathogenesis of IPF may arise from their ability to produce a variety of profibrotic factors. In this regard, tryptase, the most abundant protein in human lung MC, was found to stimulate collagen I synthesis ${ }^{21}$ and fibroblast proliferation. ${ }^{8}$ Similar cellular activities were reported on exposure of fibroblasts to TGF- $\beta 1$, bFGF, or histamine, ${ }^{22}$ which are other mediators released from activated MC. Moreover, it was shown that both tryptase and chymase are capable of activating matrix metalloproteinases, thereby contributing to extracellular matrix (ECM) turnover. ${ }^{23,24}$

Although MC mediators are known to have profibrotic properties, the molecular mechanism of their action is poorly understood. The major focus of the present study was therefore to decipher the molecular basis of MC-fibroblast interplay in the development of pulmonary fibrosis.

\section{Materials and Methods}

\section{Study Population}

The investigations were conducted according to Declaration of Helsinki principles and were approved by the local institutional ethics committee. Informed consent was obtained from either the patients or their next of kin. BALF was obtained by flexible fiberoptic bronchoscopy from 20 spontaneously breathing healthy volunteers and from 40 spontaneously breathing IPF patients. Diagnosis of IPF was decided on the basis of recently published guidelines. ${ }^{25}$ In 20 patients, diagnosis was confirmed by surgical lung biopsy, which revealed a pattern of usual interstitial pneumonia in every case. Additionally, lung tissue was obtained from 24 IPF patients who underwent lung transplantation at the Department of Cardiothoracic Surgery, Medical University of Vienna, Austria. IPF diagnosis was based on clinical criteria, as well as proof of a usual interstitial pneumonia pattern. Nonused donor lungs served as control $(n=10)$. Inflammatory processes were not observed in donor lungs by histopathological evaluation. Demographic and clinical characteristics of the patient cohort are reported elsewhere. ${ }^{26}$

\section{Isolation of Human Lung MCs}

For isolation of human lung MCs, tumor-free lung tissue obtained from patients with bronchial carcinoma undergoing lobectomy was provided by the Section of Pathology, Research Center Borstel. Approval for these studies was obtained from the institutional review board at the University of Lübeck, and informed consent was provided according to the Declaration of Helsinki.

Lung specimens were chopped into pieces and placed overnight in ice-cold MC buffer (12 mmol/L HEPES, pH 7.4, $290 \mathrm{mmol} / \mathrm{L} \mathrm{NaCl}, 3 \mathrm{mmol} / \mathrm{L} \mathrm{KCl}, 3.7 \mathrm{mmol} / \mathrm{L}$ $\mathrm{Na}_{3} \mathrm{PO}_{4} \cdot 12 \mathrm{H}_{2} \mathrm{O}, 6 \mathrm{mmol} / \mathrm{L}$ glucose, $0.1 \%$ bovine serum albumin). To disperse cells enzymatically, lung pieces were incubated in MC buffer containing $0.1 \%$ gelatin, $1.5 \mathrm{mg} / \mathrm{mL}$ dispase II, $0.375 \mathrm{mg} / \mathrm{mL}$ chymopapain (both from SigmaAldrich, Taufkirchen, Germany; St. Louis, MO), $0.75 \mathrm{mg} / \mathrm{mL}$ collagenase type I, $1.79 \mathrm{mg} / \mathrm{mL}$ elastase (both from Worthington, Lakewood, NJ) under agitation for 4 hours at $37^{\circ} \mathrm{C}$. MCs were enriched by Percoll gradient centrifugation followed by immunoaffinity magnetic enrichment, using antiphycoerythrin-conjugated microbeads (Miltenyi Biotec, Bergisch-Gladbach, Germany; Auburn, CA) in combination with phycoerythrin-conjugated mAb 97A6 (IOTest; Beckman Coulter-Immunotech, Marseille, France; Fullerton, CA) specific for CD203c. The purity of MCs used for experiments ranged from $88 \%$ to $100 \%$ as assessed by Toluidine Blue staining. Viability was always $>85 \%$ as assessed by Trypan Blue exclusion. Purified MCs $\left(5 \times 10^{5} / \mathrm{mL}\right)$ were cultured in StemPro medium (Life TechnologiesInvitrogen, Carlsbad, CA) containing $2 \mathrm{mmol} / \mathrm{L} \mathrm{L}$-glutamine, $50 \mathrm{IU} / \mathrm{mL}$ penicillin, $50 \mu \mathrm{g} / \mathrm{mL}$ streptomycin, and $100 \mathrm{ng} / \mathrm{mL}$ human recombinant SCF (PeproTech, London, UK; Rocky Hill, NJ). MCs taken from culture 5 days after isolation were washed with fetal calf serum-free medium and were seeded onto confluent serum-starved human lung fibroblasts (HLFs) at a $1: 2$ ratio. When required, $100 \mathrm{nmol} / \mathrm{L}$ of the $\mathrm{CD} 117$ inhibitor ISCK03 (Santa Cruz Biotechnology, Santa Cruz, CA), $10 \mu \mathrm{g} / \mathrm{mL}$ anti-human SCF (R\&D Systems, Wiesbaden, Germany; Minneapolis, MN), or $10 \mu \mathrm{g} / \mathrm{mL}$ isotype $\mathrm{IgG}$ control (R\&D Systems) was included. MC numbers during the coculture period were assessed using Kimura staining, which readily differentiates red metachromatic MCs from unlabeled HLFs. MC monoculture controls were established in parallel.

To investigate tryptase release, MCs were incubated with control or IPF HLFs in Dulbecco's modified Eagle's medium alone or in the presence of $2 \mu \mathrm{g} / \mathrm{mL}$ compound 48/80 (C48/80; Sigma-Aldrich), or were challenged with BALF obtained from healthy control subjects or IPF 
patients. After 4 hours, cells and supernatants were separated by centrifugation and supernatants were analyzed for the presence of tryptase by Western blotting.

\section{HLF Isolation and Stimulation}

HLFs were isolated from control (donor) and IPF lungs, as described previously. ${ }^{27}$ HLFs were either not stimulated or were stimulated for various time periods with different concentrations of tryptase ( 0.5 to $4 \mathrm{nmol} / \mathrm{L} ; \mathrm{R} \& \mathrm{D}$ Systems $)$. In some experiments, cells were transfected with $100 \mathrm{nmol} / \mathrm{L}$ human proteinase activated receptor 2 (PAR-2) siRNA (Santa Cruz Biotechnology), human PKC- $\alpha$ siRNA (Ambion; Life Technologies, Austin, TX), or universal negative control siRNA (Ambion; Life Technologies) using siLentFect lipid reagent (Bio-Rad Laboratories, Munich, Germany; Hercules, CA) 48 hours before the addition of $2 \mathrm{nmol} / \mathrm{L}$ tryptase. In other experiments, cells were pretreated with the PAR-2 antagonist ENMD-1068 (Enzo Life Sciences, Lörrach, Germany; Farmingdale, NY), Gö 6976, Ro 32-0432, Raf-1 inhibitor, or PD 98059 (all from Calbiochem; EMDMillipore, Darmstadt, Germany; Billerica, MA) 1 hour before exposure to $2 \mathrm{nmol} / \mathrm{L}$ tryptase.

\section{Cell Proliferation Assay}

Proliferation of HLFs was determined by a DNA synthesis assay based on the uptake of $\left[{ }^{3} \mathrm{H}\right]$ thymidine (Amersham; GE Healthcare, Freiburg, Germany; Little Chalfont, UK). Cells were cultured in 48-well plates, growth-arrested in serum-free Dulbecco's modified Eagle's medium, and left unstimulated or stimulated for 24 hours in serum-free medium with 0.5 to $4 \mathrm{nmol} / \mathrm{L}$ tryptase, $65 \mathrm{U} / \mathrm{L}$ thrombin (American Diagnostica; Sekisui Diagnostics, Lexington, MA), $100 \mu \mathrm{mol} / \mathrm{L}$ PAR-2 agonist peptide (2-furoylLIGRLO-NH2), or $100 \mu \mathrm{mol} / \mathrm{L}$ scrambled peptide control (trans-cinnamoyl-OLIGRL-NH2) (both of the latter kindly provided by Dr. A. Meinhardt, Justus-Liebig-University, Giessen, Germany). Subsequently, the cells were pulsed with $1.2 \mu \mathrm{Ci} / \mathrm{mL}\left[{ }^{3} \mathrm{H}\right]$ thymidine for 16 hours. Afterward, cells were solubilized in $0.5 \mathrm{~mol} / \mathrm{L} \mathrm{NaOH}$, and $\left[{ }^{3} \mathrm{H}\right]$ thymidine incorporation was determined by liquid scintillation spectrometry. In some experiments, ENMD-1068, Gö 6976, Ro 32-0432, Raf-1 inhibitor, or PD 98059 (Calbiochem; EMD-Millipore) was added to the cells 1 hour before stimulation. In other experiments, cells were transfected with human PAR-2 siRNA (Santa Cruz Biotechnology), human PKC- $\alpha$ siRNA, or universal negative control siRNA $(100 \mathrm{nmol} / \mathrm{L}$ each; Ambion; Life Technologies) 48 hours before the proliferation assay.

\section{MC-Induced HLF Proliferation}

HLFs were seeded at a density of 10,000 cells per well in 48-well plates. Cocultures were initiated by introducing human lung MCs to HLFs at a 1:2 ratio. Cocultures were maintained in Dulbecco's modified Eagle's medium alone or with additives $[2 \mu \mathrm{g} / \mathrm{mL}$ C48/80 (Sigma-Aldrich) and APC366 (R\&D Systems)] for various time periods. In some experiments, HLFs were pretreated with $50 \mu \mathrm{g} / \mathrm{mL}$ of the PAR-2 antagonist ENMD-1068 (Calbiochem; EMDMillipore) 1 hour before incubation with MCs. In other experiments, PAR-2 was depleted in HLFs 48 hours before incubation with MCs. At the end of the coculture experiments, MCs were washed away and HLFs were subjected to measurement of $\left[{ }^{3} \mathrm{H}\right]$ thymidine incorporation.

\section{SCF Antigen Level}

SCF antigen level was determined in BALF samples of IPF patients and healthy control subjects using a human SCF enzyme-linked immunosorbent assay kit (R\&D Systems) according to the manufacturer's instructions.

\section{RNA Isolation and RT-qPCR}

RNA isolation and quantitative real-time RT-PCR (RTqPCR) were performed as described previously. ${ }^{28}$ The following oligonucleotide primers were used: human soluble stem cell factor $\left(\mathrm{SCF}_{\mathrm{S}}\right)$ forward, 5'-GGACTTTGTAGTGGCATCTGAA- ${ }^{\prime}$, human $\mathrm{SCF}_{\mathrm{S}}$ reverse, $5^{\prime}$-CTAAGGGAGCTGGCTGCAA-3'; human transmembrane $\mathrm{SCF}\left(\mathrm{SCF}_{\mathrm{TM}}\right)$ forward, 5'-CCTGAGAAAGGGAAGGCCAA-3', human $\mathrm{SCF}_{\mathrm{TM}}$ reverse, 5'-CTTATACTGGAAGAAGAGA-3'; human fibronectin $(\mathrm{FN})$ forward, $5^{\prime}$-TGTACTTCTGAGGGTCGCAGG-3' ${ }^{\prime}$, human FN reverse, 5'-CCAATGCGATACATGACCCC-3'; human collagen I forward, 5'-CAAGAGGAAGGCCAAGTCGAG-3'; human collagen I reverse; 5' TTGTCGCAGACGCAGATCC-3'; human $\alpha$-SMA forward, $5^{\prime}$-CGAGATCTCACTGACTACCTCATGA-3'; human $\alpha$ SMA reverse, 5'-AGAGCTACATAACACAGTTTCTCCTTGA-3; human $\beta$-actin forward: $5^{\prime}$-ATTGCCGACAGGATGCAGGAA- ${ }^{\prime}$, human $\beta$-actin reverse: 5'-GCTGATCCACATCTGCTGGAA- $3^{\prime}$. $\beta$-actin was used as the reference gene. Cycling conditions were $95^{\circ} \mathrm{C}$ for 6 minutes, followed by 40 cycles of $95^{\circ} \mathrm{C}$ for 20 seconds, $58^{\circ} \mathrm{C}$ for 30 seconds, and $73^{\circ} \mathrm{C}$ for 30 seconds. Melting-curve analysis and gel electrophoresis were performed to confirm the exclusive amplification of the expected PCR product.

\section{Western Blotting}

Lung tissue samples or cells were lysed in ice-cold lysis buffer $[20 \mathrm{mmol} / \mathrm{L}$ Tris $\mathrm{pH} 7.5,150 \mathrm{mmol} / \mathrm{L} \mathrm{NaCl}, 1 \mathrm{mmol} / \mathrm{L}$ EDTA, $1 \mathrm{mmol} / \mathrm{L}$ EGTA, $1 \%$ Triton X-100, $2.5 \mu \mathrm{mol} / \mathrm{L}$ Na-pyrophosphate, $1 \mathrm{mmol} / \mathrm{L} \beta$-glycerophosphate, $1 \mathrm{mmol} / \mathrm{L}$ $\mathrm{Na}_{3} \mathrm{VO}_{4}, 1 \mathrm{mmol} / \mathrm{L}$ phenylmethylsulfonyl fluoride, $1 \mu \mathrm{g} / \mathrm{mL}$ Complete Protease Inhibitor Cocktail (Roche Applied Science, Indianapolis, IN)]. Protein lysates were separated on a 10\% SDS polyacrylamide gel under reducing conditions, followed by electrotransfer to a polyvinylidene difluoride membrane. After blocking, the membranes were probed with 
one of the following antibodies: mouse anti-MC tryptase (R\&D Systems), rabbit anti-SCF, mouse anti-FN, rabbit anti-histone H2B (all from Abcam, Cambridge, MA), mouse antiphospho-p44/42, rabbit anti-phospho-PKC(pan), rabbit antiphospho-PKC- $\delta$ (Thr 505), rabbit anti-phospho-Raf-1 (all from Cell Signaling Technology, Danvers, MA), rabbit antiEGFR, rabbit anti-phospho-PKC- $\alpha$ (Thr 638; Biomol; Enzo Life Sciences, Hamburg, Germany; Plymouth Meeting, PA), or rabbit anti-phospho-PKC- $\varepsilon$ (Ser 729; Life Technologies, Darmstadt, Germany; Carlsbad, CA). Membranes were then incubated with peroxidase-labeled secondary antibodies (all from Dako, Glostrup, Denmark). Final detection of proteins was performed using an ECL Plus kit (Amersham; GE Healthcare, Freiburg, Germany). To determine the amounts of protein loaded on the gel, blots were stripped and reprobed using mouse anti- $\beta$-actin (Sigma-Aldrich), rabbit anti-p44/42, rabbit antiRaf-1, rabbit anti-PKC- $\alpha$, rabbit anti-PKC- $\varepsilon$, or rabbit anti-PKC- $\delta$ (all from Cell Signaling Technology).

\section{Toluidine Blue Staining}

Under a standard protocol, paraffin-embedded lung tissue sections ( $3 \mu \mathrm{m}$ thick) from IPF patients and control subjects were stained with Toluidine Blue to identify MCs. The tissue sections were dewaxed, rehydrated, and incubated with $0.05 \%(\mathrm{w} / \mathrm{v})$ Toluidine Blue for 2 to 3 minutes. The number of MCs in each section was counted, and MCs were identified as granulated or degranulated. The index of degranulation, which is calculated as the number of degranulated MCs divided by the number of granulated MCs, was determined as described previously ${ }^{29}$ and was expressed as a percentage, assuming $100 \%$ for control subjects. The MC analysis was done by investigators masked to patient versus control group (B.K.D. and D.K.).

\section{Immunohistochemistry}

Paraffin-embedded lung tissue sections ( $5 \mu \mathrm{m}$ thick) from IPF patients and control subjects were deparaffinized in xylene and rehydrated through graded ethanol washes. Antigen retrieval was performed by cooking tissue sections for 30 minutes in Tris-EDTA buffer ( $10 \mathrm{mmol} / \mathrm{L}$ Tris, $\mathrm{pH} 9.0,1 \mathrm{mmol} / \mathrm{L}$ EDTA $)$. Immunohistochemistry was performed using a ZytoChemPlus AP polymer kit according to the manufacturer's instructions (Zymed Laboratories, San Francisco, CA). The following primary antibodies were used: mouse anti-MC tryptase, rabbit anti-SCF (both from Abcam), or mouse anti- $\alpha$-SMA (SigmaAldrich). For negative control, the primary antibody was replaced with a species-matched isotype control. In the illustrations, images are representative of at least six other areas per section, seen on at least three independent sections per patient. Tryptase-positive MCs in each section were counted using a light microscope. The mean number of tryptase-positive MCs was expressed as a percentage, assuming 100\% in control subjects. The MC analysis was done by investigators masked to patient versus control group (B.K.D. and D.K.).

\section{Immunocytochemistry}

For immunocytochemical analysis, HLFs were stimulated with $2 \mathrm{nmol} / \mathrm{L}$ tryptase for 30 minutes. After a PBS wash, the cells were fixed with $4 \%$ paraformaldehyde for 10 minutes, permeabilized with $0.2 \%$ Triton X-100 in PBS for 10 minutes, blocked with $3 \%$ bovine serum albumin in PBS for 1 hour at room temperature, and incubated overnight at $4{ }^{\circ} \mathrm{C}$ with rabbit anti-PKC- $\alpha$ antibody (Biomol; Enzo Life Sciences). Slides were then incubated with Alexa Fluor 568-conjugated secondary antibody (Dianova, Hamburg, Germany) and mounted with Vectashield mounting medium (Vector Laboratories, Burlingame, CA). Nuclei were visualized by DAPI (Sigma-Aldrich) staining. For negative control, the primary antibody was replaced by a speciesmatched isotype control. Images were captured under a Leica DMR microscope (Leica Microsystems, Wetzlar, Germany) with a $40 \times$ objective.

\section{Statistical Analysis}

Statistical analyses of in vitro data were performed using one-way analysis of variance followed by Tukey's honestly significant difference post hoc test. Clinical data are expressed as median and interquartile range; box-andwhisker-plots indicate the median, first, and third quartile, with the whiskers extended to the most extreme value inside the 1.5-fold interquartile range. Statistical analyses of clinical data were performed using Wilcoxon rank sum test. The level of statistical significance was set at $P \leq 0.05$.

\section{Results}

The Number of Degranulated MCs Is Elevated in Lungs of IPF Patients

Previous studies have demonstrated increased numbers of MCs in lungs of IPF patients. ${ }^{17-19}$ In accord with these reports, we also observed elevated number of MCs in IPF lungs (Figure 1A); moreover, the majority of MCs in IPF lungs were activated, as evinced by an increased index of degranulation (Figure 1B). Because tryptase-positive MCs are the dominant $\mathrm{MC}$ type in human peripheral lung, we subsequently evaluated the number of tryptase-positive cells in the lungs of IPF patients and control subjects. Staining of serial IPF lung tissue sections with Toluidine Blue and for tryptase demonstrated that Toluidine Blue-stained MCs are also tryptase-positive (Figure 1C). Consistently, the number of tryptase-positive cells was elevated in the lungs of IPF patients, compared with control subjects (Figure 1D). Tryptase-positive cells were located in close proximity to fibroblast foci and hyperplastic alveolar type II cells (Figure 1E). Moreover, Western blot analysis revealed increased tryptase levels in IPF lung homogenates (Figure 1, F and G). 


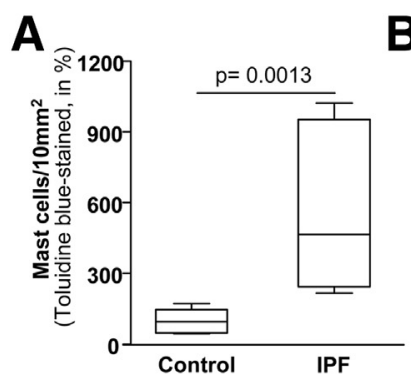

D

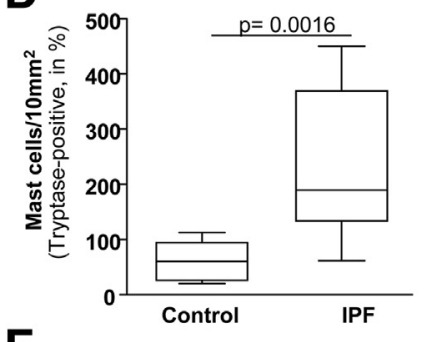

$\mathbf{F}$

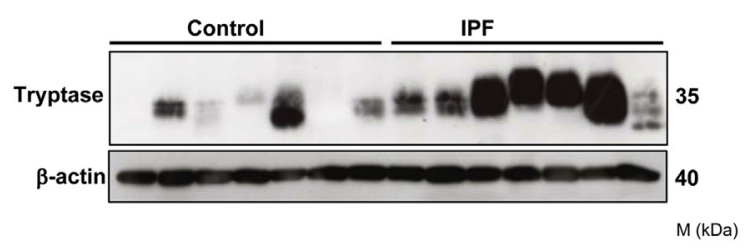

$\mathbf{E}$
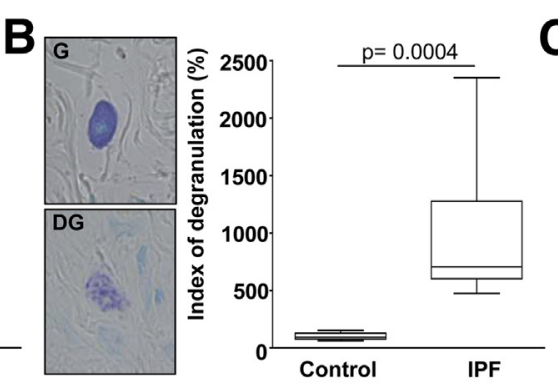

C
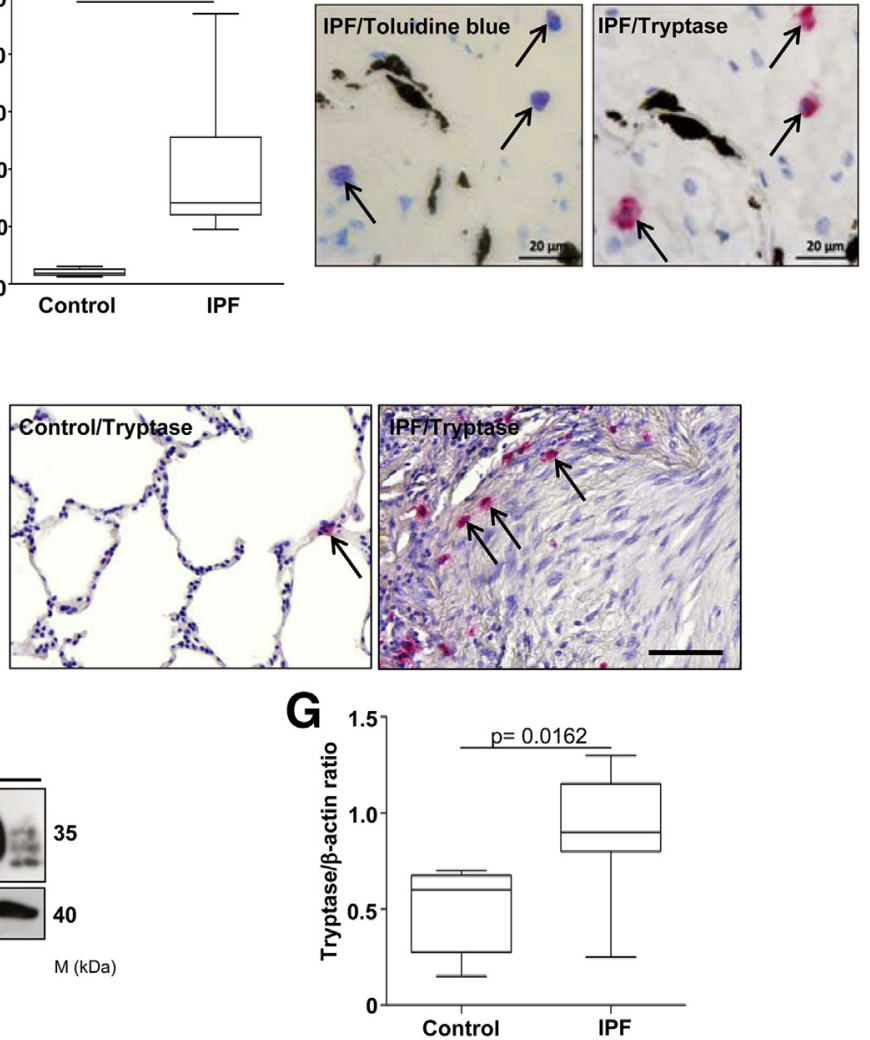

Figure 1 Elevated numbers of degranulated MCs in the lungs of IPF patients. A: Total number of MCs is increased in lungs of IPF patients, compared with control subjects. B: The index of degranulation (defined under Materials and Methods) is increased in lungs of IPF patients, compared with control subjects. C: Toluidine Blue and tryptase staining of serial IPF lung tissue sections. Positive staining is indicated by arrows. D: Total number of tryptase-positive MCs, in lungs of IPF patients and control subjects. E: Lung tissue sections from control subjects and IPF patients stained for tryptase. Tryptase-positive MCs are indicated by arrows. F: Tryptase levels in lung homogenates of control subjects and IPF patients as assessed by Western blotting. Representative blots are shown for control subjects (7/10) and IPF patients (7/24). G: Densitometric analysis of data in panel $\mathbf{F}$. Data are expressed as box-and-whisker plots (defined under Statistical Analysis). $n=9$ per group (A, B, and D). Scale bars: $20 \mu \mathrm{m}$ (C); $50 \mu \mathrm{m}$ (E). Original magnification, $\times 100$ (B).

\section{Tryptase Released from Human Lung MCs Increases Proliferation of HLFs}

To assess the role of MCs in the proliferation of HLFs, we performed coculture experiments with isolated human lung MCs and HLFs from IPF patients and control subjects. Coincubation of MCs with HLFs induced HLF proliferation (Figure 2A). Notably, IPF fibroblasts displayed a significantly more enhanced growth rate, compared with control fibroblasts (Figure 2A). Furthermore, coculture of HLFs with MCs induced MC degranulation, as evinced by the presence of tryptase in cell culture medium (Figure 2B). These effects were enhanced when MCs were additionally activated by C48/80 (Figure 2, A and B). Because no major difference in the extent of $\mathrm{MC}$ activation between donor and IPF HLFs was observed, we considered that factors produced by other cell types might contribute to the elevated number of degranulated MCs observed in IPF lungs, compared with control subjects. Consistent with this notion, potentiated degranulation of MCs was observed on their incubation with BALF obtained from IPF patients, compared with BALF derived from healthy control subjects
(Figure 2C). A role of tryptase in the induction of mitogenic activities on HLFs was supported by our observation that HLF proliferation induced by activated MCs was attenuated in the presence of the tryptase inhibitor APC366 (Figure 2D). Remarkably, APC366 inhibitor was not able to entirely reverse MC-triggered mitogenic activities toward HLFs (not even at the high concentration of $100 \mu \mathrm{mol} / \mathrm{L}$ ), indicating that other MC-derived mediators, besides tryptase, are responsible for the remaining increase in fibroblast proliferation (Figure 2D).

\section{Tryptase-Induced Proliferation of HLFs Depends on PAR-2}

To confirm the role of tryptase in MC-induced HLF mitogenic activities and to investigate the underlying molecular mechanisms in detail, we next examined proliferation of HLFs after stimulation with this protease. Tryptase increased HLF proliferation in a dose-dependent manner, as evinced by enhanced $\left[{ }^{3} \mathrm{H}\right]$ thymidine incorporation assay (Figure 3A). To determine the potential role of the protease activated receptor-2 (PAR-2), which was recently shown to 
mediate cellular responses to tryptase,${ }^{30}$ in tryptase-induced HLF proliferation, HLFs were pretreated with the PAR-2 antagonist ENMD-1068 before exposure to tryptase. Preincubation of HLFs with ENMD-1068 abolished tryptaseinduced mitogenic activities in a dose-dependent manner (Figure 3B). Of note, pretreatment of HLFs with ENMD-1068 did not influence the proliferation rate induced by thrombin (factor IIa), which activates all PARs except PAR-2, indicating

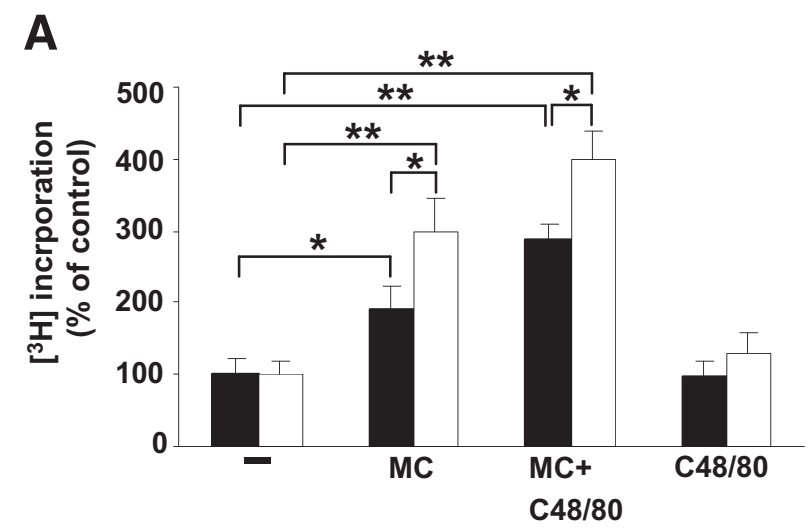

B
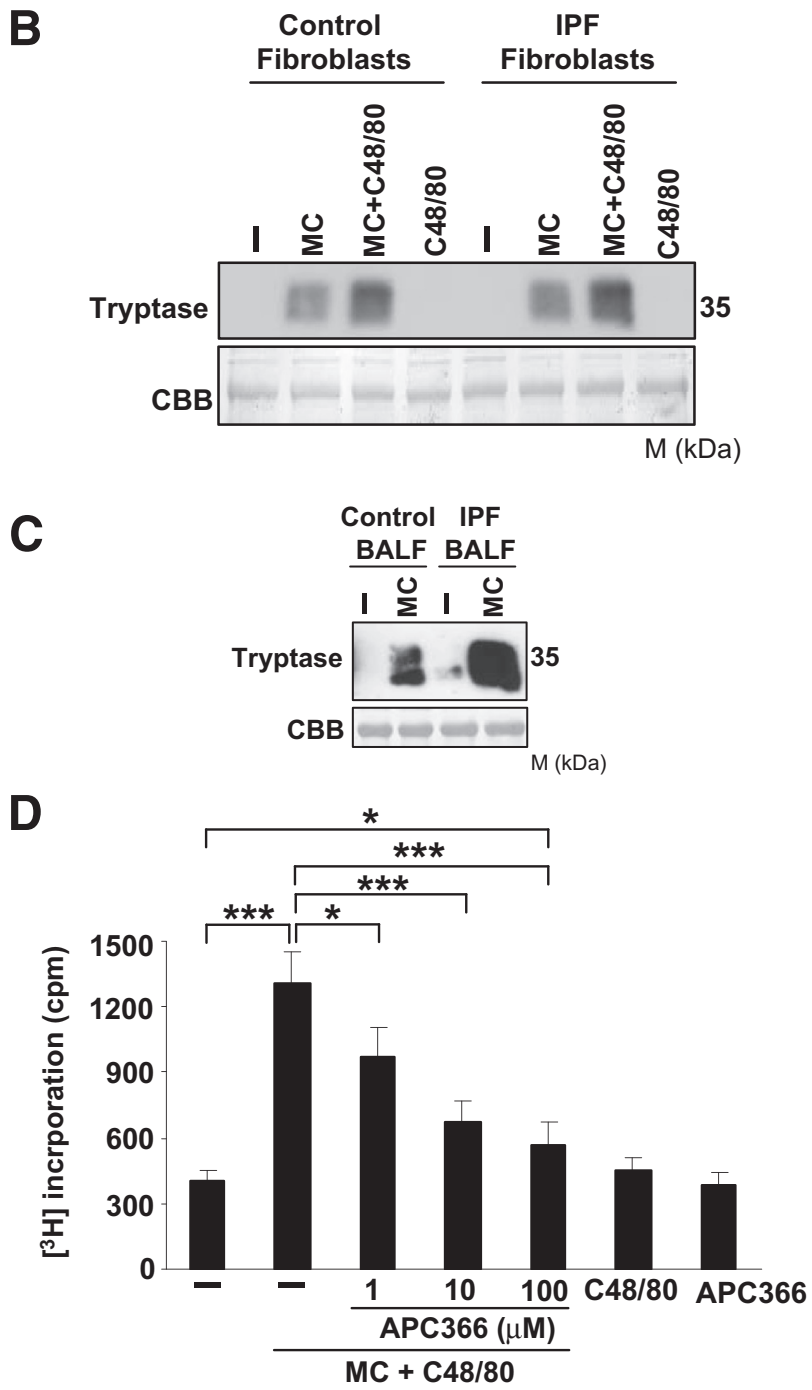

PAR-2 antagonist specificity (Figure 3B). In accord, coculture studies demonstrated inhibition of HLF proliferation in response to activated MCs in the presence of ENMD-1068 (Figure 3C). To confirm a crucial role of PAR-2 in tryptaseinduced HLF proliferation, HLFs were transfected with PAR-2-specific siRNA (siPAR-2). Depletion of PAR-2 strongly inhibited mitogenic activities of tryptase toward HLFs (Figure 3D). Similar results were obtained when activated MCs were applied (Figure 3E). Taken together, these data suggest that PAR-2 mediates tryptase-induced proliferation of HLFs.

Tryptase Stimulates Proliferation of HLFs via the PKCa/Raf-1/P44/42 Signaling Pathway

To further decipher the molecular mechanisms responsible for tryptase-induced HLF proliferation, we analyzed activation of various protein kinases on exposure to this protease. Tryptase induced phosphorylation of PKC(pan), Raf-1, and p44/42 in a time-dependent manner (Figure 4A). In contrast, no activation of SAPK/JNK, p38, or Akt was observed (data not shown). Because lung fibroblasts are known to express three PKC isoforms (ie, PKC- $\alpha$, PKC- $\delta$, and $\mathrm{PKC}-\varepsilon),{ }^{31,32}$ we investigated activation of these isoforms on exposure of HLFs to tryptase. Treatment of HLFs with tryptase induced rapid phosphorylation of PKC- $\alpha$, but did not activate PKC- $\delta$ or PKC- $\varepsilon$ (Figure 4B). Furthermore, translocation of $\mathrm{PKC}-\alpha$ from the cytoplasm to the nucleus was observed after stimulation of HLFs with tryptase, as shown by Western blotting (Figure 4C) and immunofluorescence staining (Figure 4D). Consistently, diminished phosphorylation of PKC- $\alpha$, Raf- 1 , and p44/42 in response to tryptase was noted when HLFs were pretreated with the PAR-2 antagonist ENMD-1068 (Figure 4E) or when PAR-2 was knocked down (Figure 4F). PKC knockdown efficiency was assessed by Western blotting (Figure 4G).

To examine the importance of the PKC- $\alpha /$ Raf- $1 / \mathrm{p} 44 / 42$ pathway in tryptase-induced HLF proliferation, we applied pharmacological inhibitors of the aforementioned protein kinases. Gö 6976, an inhibitor of PKC- $\alpha$ and PKC- $\beta$, diminished tryptase-triggered mitogenic activities of HLFs in a dosedependent manner (Figure 5A). Because lung fibroblasts do

Figure 2 Tryptase released from MCs stimulates proliferation of HLFs. A: Proliferation of control (black bars) and IPF (white bars) HLFs in the presence of MCs alone or MCs activated by $2 \mu \mathrm{g} / \mathrm{mL}$ C48/80. Proliferation of HLFs was assessed by $\left[{ }^{3} \mathrm{H}\right]$ thymidine incorporation. B: Release of tryptase into culture medium on coincubation of control or IPF HLFs with MCs alone or with MCs activated by $2 \mu \mathrm{g} / \mathrm{mL}$ C48/80. Representative Western blots are shown. C: Release of tryptase on incubation of MCs with BALF obtained from IPF patients or from healthy control subjects. Representative Western blots are shown. D: HLFs were cocultured with activated MCs in the absence or presence of various concentrations $(1,10$, or $100 \mu \mathrm{mol} / \mathrm{L})$ of the tryptase inhibitor APC366. Cell proliferation was assessed by $\left[{ }^{3} \mathrm{H}\right]$ thymidine incorporation. Data are expressed as means \pm SD from five independent experiments. ${ }^{*} P<0.05$, ${ }^{* *} P<0.01$, and ${ }^{* *} P<0.001 . n=3$ per group (B); $n=5$ per group (C). 

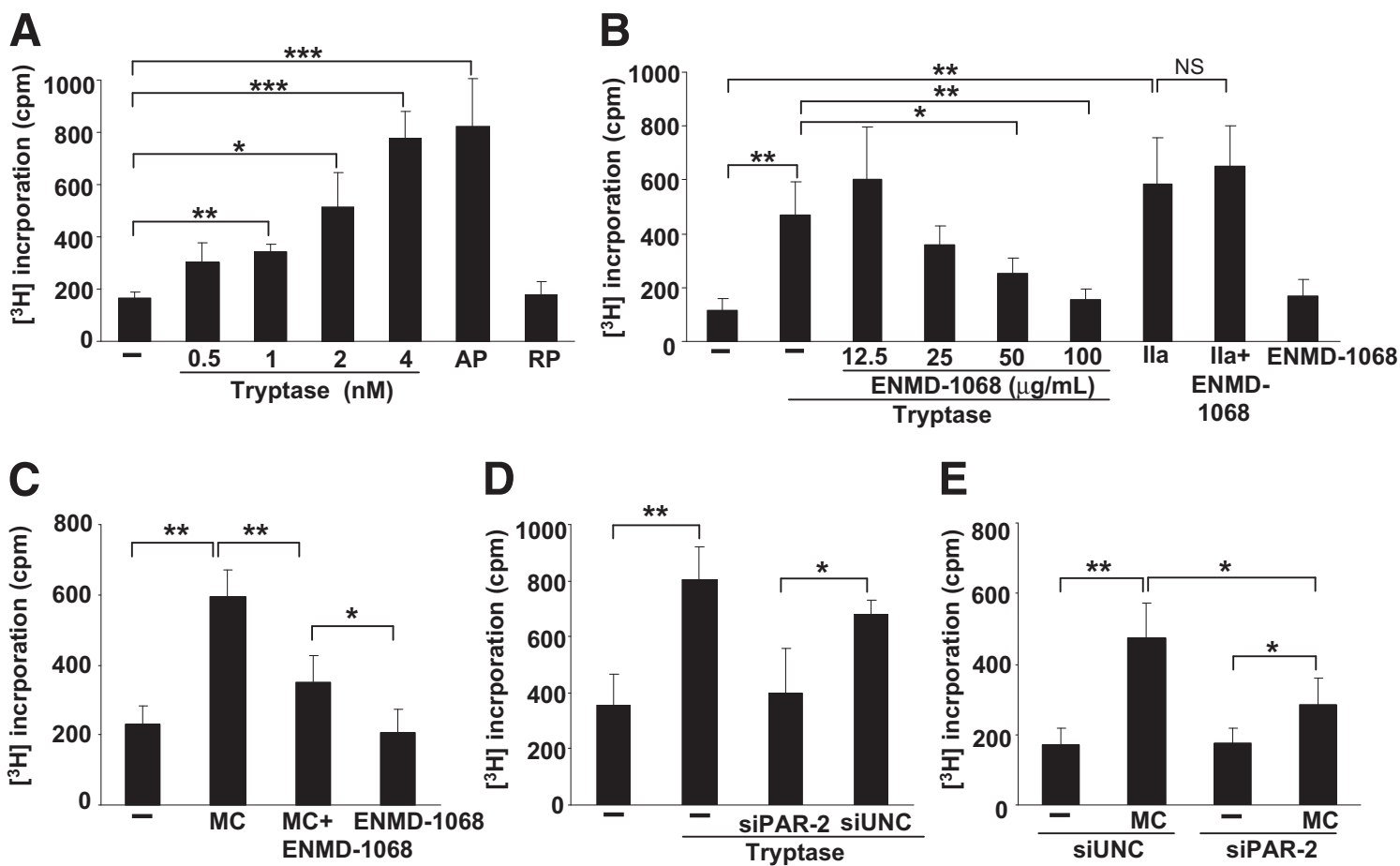

Figure 3 PAR-2 mediates proliferation of HLFs in response to tryptase. Cell proliferation was assessed by $\left[{ }^{3} \mathrm{H}\right]$ thymidine incorporation. A: Proliferation of control HLFs stimulated for 24 hours with various concentrations of tryptase $(0.5,1,2$, or $4 \mathrm{nmol} / \mathrm{L}), 100 \mu \mathrm{mol} / \mathrm{L}$ PAR-2 peptide agonist (AP), or $100 \mu \mathrm{mol} / \mathrm{L}$ scrambled peptide control (RP). B: HLFs were treated with various concentrations of the PAR-2 antagonist ENMD-1068 $(12.5,25,50$, or $100 \mu \mathrm{g} / \mathrm{mL})$ for $1 \mathrm{hour}$ before incubation with $2 \mathrm{nmol} / \mathrm{L}$ tryptase or $65 \mathrm{U} / \mathrm{L}$ thrombin. C: HLFs were pretreated with $50 \mu \mathrm{g} / \mathrm{mL}$ of the PAR-2 antagonist ENMD-1068 for 1 hour before the addition of C48/80-activated MCs. D: Effect of PAR-2 depletion on $2 \mathrm{nmol} / \mathrm{L}$ tryptase-induced proliferation of HLFs. E: Proliferation of PAR-2 depleted HLFs in the presence of $C 48 / 80$-activated MCs. Data are expressed as means \pm SD from three (E), four (C and $\mathbf{D})$, or five (A and $\mathbf{B})$ independent experiments. ${ }^{*} P<0.05,{ }^{* *} P<0.01$, and ${ }^{* * *} P<0.001$. siUNC, universal negative control siRNA.

not express PKC- $\beta$, decrease in HLF proliferation was an effect of PKC- $\alpha$ inhibition. Moreover, similar results were obtained when Ro 32-0432, a specific inhibitor of PKC- $\alpha$, was used (Figure 5B). Consistently, knockdown of PKC- $\alpha$ abolished proliferation of HLFs in response to tryptase (Figure 5C). Tryptase-induced mitogenic activities of HLFs were also inhibited in the presence of Raf-1 inhibitor (Figure 5D) or of PD 98059, an inhibitor of the MEK1/2/p44/42 pathway (Figure 5E). In addition, depletion of PKC- $\alpha$ diminished phosphorylation of Raf-1 and p44/42, suggesting its upstream position in the signaling cascade triggered by tryptase (Figure 5F). Taken together, these data suggest that the PKC- $\alpha /$ Raf-1/p44/42 pathway plays an essential role in tryptaseinduced proliferation of HLFs.

Tryptase Potentiates FN and Collagen I Production by HLFs Independently of PKC $-\alpha$, Raf- 1 , and P44/42 Activities

Next to fibroblast proliferation, increased ECM deposition is another typical feature of IPF. This prompted us to examine the induction of ECM protein expression in HLFs on exposure to tryptase. Stimulation of HLFs with tryptase did not affect FN and collagen I mRNA levels within 24 hours of tryptase treatment (Figure 6A); however, it did potentiate $\mathrm{FN}$ and collagen I protein production. FN protein synthesis peaked at 48 hours and slightly declined thereafter, whereas collagen I protein expression gradually increased over the entire stimulation period of 72 hours (Figure 6, B and C). These results suggest that FN and collagen I gene transcription activities are not involved and that increases in FN and collagen I protein levels are due to the effect of tryptase on FN and collagen mRNA translation and/or protein stability. Preincubation of HLFs with the PAR-2 antagonist ENMD-1068 abolished tryptase-triggered FN and collagen I protein synthesis (Figure 6, D and E). Similar results were obtained when PAR-2 was knocked down (Figure 6, F and G). In contrast, no change in FN and collagen I protein levels was observed when HLFs were exposed to Raf-1, PKC- $\alpha$, or MEK1/2 inhibitors before the addition of tryptase (Figure 6, H and I). Exposure of HLFs to tryptase did not stimulate expression of the myofibroblast marker $\alpha$-SMA (Supplemental Figure S1), indicating that tryptase does not induce differentiation of lung fibroblasts to a myofibroblast phenotype.

The Levels of Transmembrane Form of SCF Are Elevated in Lungs of IPF Patients

SCF is a major growth factor for MCs, important for their homing proliferation, survival, and differentiation. SCF can be found in either a soluble or a transmembrane form, 
A

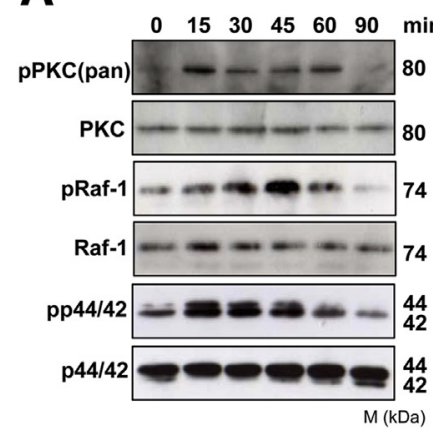

B

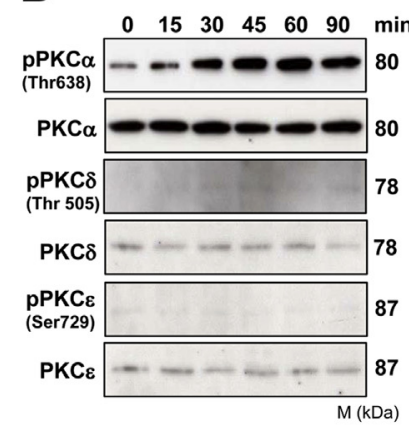

C

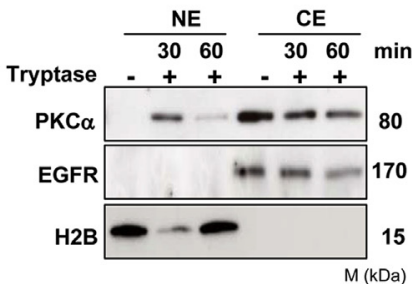

D

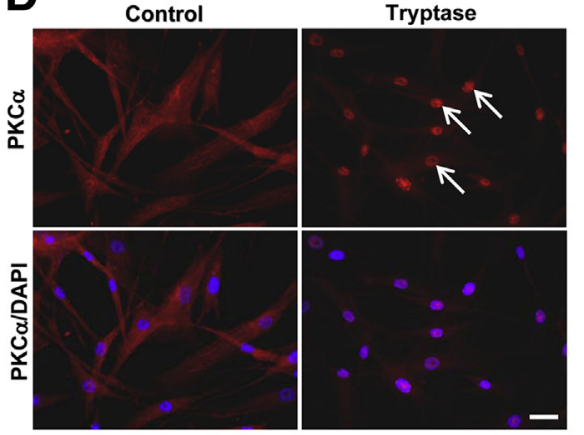

E

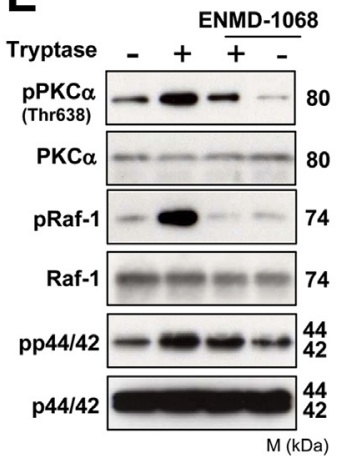

$\mathbf{F}$

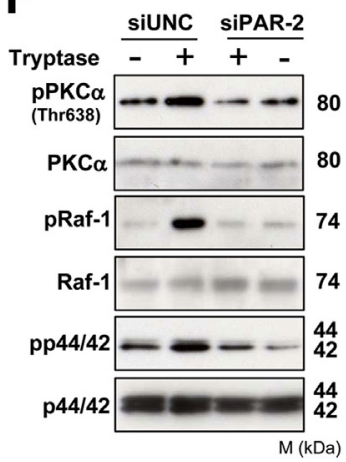

G

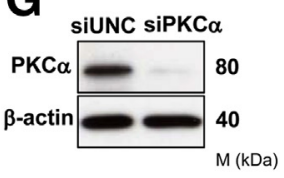

Figure 4 Tryptase activates the PKC- $\alpha /$ Raf-1/p44/42 signaling pathway in HLFs. A: Control HLFs were treated for 0 to 90 minutes with $2 \mathrm{nmol} / \mathrm{L}$ tryptase, and the activation of PKC(pan), Raf-1, and p44/42 kinases as assessed by phosphorylation was analyzed by Western blotting. Equal loading was confirmed with pan-specific antibodies. B: Time-dependent phosphorylation of PKC isoforms (PKC- $\alpha$, PKC- $\delta$, PKC- $\varepsilon$ ) in response to 2 nmol/L tryptase was analyzed by Western blotting. C: Western blot analysis of $2 \mathrm{nmol} / \mathrm{L}$ tryptase-driven translocation of PKC- $\alpha$ into the nucleus of HLFs. Epidermal growth factor receptor (EGFR) was used to assess the purity of the nuclear fraction and histone $\mathrm{H} 2 \mathrm{~B}$ was used to assess the purity of the cytosolic fraction. CE, cytoplasmic extract; $\mathrm{NE}$, nuclear extract. D: Tryptase-dependent translocation of PKC- $\alpha$ into the nucleus of HLFs was assessed by immunofluorescence. Nuclear localization of PKC- $\alpha$ is indicated by arrows. $\mathbf{E}$ and $\mathbf{F}$ : Activation of PKC- $\alpha$, Raf-1, and p44/42 in response to $2 \mathrm{nmol} / \mathrm{L}$ tryptase in HLFs pretreated with $50 \mu \mathrm{g} / \mathrm{mL}$ of the PAR-2 antagonist ENMD1068 (E) or in HLFs depleted of PAR-2 (F). G: Knockdown efficiency in HLFs after transfection with siRNA against PKC- $\alpha$ (siPKC- $\alpha$ ) was assessed by Western blotting. Data are representative of three $(\mathbf{C}-\mathbf{G})$, four $(\mathbf{B})$, or five $(\mathbf{A})$ independent experiments. Scale bar $=10 \mu \mathrm{m}$.

resulting from alternative splicing. The two forms have distinct biological activities. ${ }^{33}$ We initially examined distribution and expression of SCF in the lungs of IPF patients. Immunohistochemical analysis revealed SCFpositive staining in control lungs in alveolar epithelial cells and alveolar macrophages, whereas in IPF lungs SCF was localized predominately to hyperplastic alveolar type II cells and to fibroblasts/myofibroblasts (Figure 7A). mRNA levels of the $\mathrm{SCF}_{\mathrm{TM}}$ form, but not the $\mathrm{SCF}_{\mathrm{S}}$ form, were elevated in the lung homogenates of IPF patients, compared with control subjects (Figure 7, B and C). Concomitantly, increased SCF protein levels were detected in IPF lung tissue (Figure 7, D and E) but not in IPF BALF samples (Figure 7F). Elevated mRNA expression of $\mathrm{SCF}_{\mathrm{TM}}$ was also observed in fibroblasts isolated from IPF lungs, compared with expression in fibroblasts isolated from control lungs (Figure 7G).

\section{Coculture of IPF HLFs with MCs Enhances MC Survival and Proliferation}

Next, we examined whether coculture of HLFs with MCs influences MC survival and proliferation. When MCs were incubated in culture medium alone, their number rapidly diminished (Figure 8A). Remarkably, when they were cocultured with HLFs, not only did the MCs survive but they even proliferated, as evinced by increased cell counts. Moreover, this effect was strongly potentiated when MCs were cocultured with fibroblasts isolated from IPF lungs, compared with control HLFs (Figure 8A). To address whether IPF HLF-induced MC survival and proliferation requires cell-to-cell contact or soluble factors only, MCs were cultured in IPF HLF-conditioned medium generated over 3 days. The soluble mediators within the medium maintained MC survival over 6 days, but they did not induce MC proliferation (Figure $8 \mathrm{~B}$ ). Taken together, these results suggest that IPF HLF-stimulated MC proliferation is cell-contact dependent. Because increased expression of $\mathrm{SCF}_{\mathrm{TM}}$ was found in IPF HLFs, we next examined the importance of this growth factor and its receptor, c-Kit (CD117), in IPF HLF-mediated MC proliferation. Addition of anti-SCF neutralizing antibody or c-Kit inhibitor markedly diminished MC proliferation in IPF HLF coculture and reduced the number of surviving $\mathrm{MCs}$ in monoculture (Figure 8, C and D). These data indicate that the $\mathrm{SCF}_{\mathrm{TM}}$ form displayed on HLFs binds to the c-Kit receptor on 

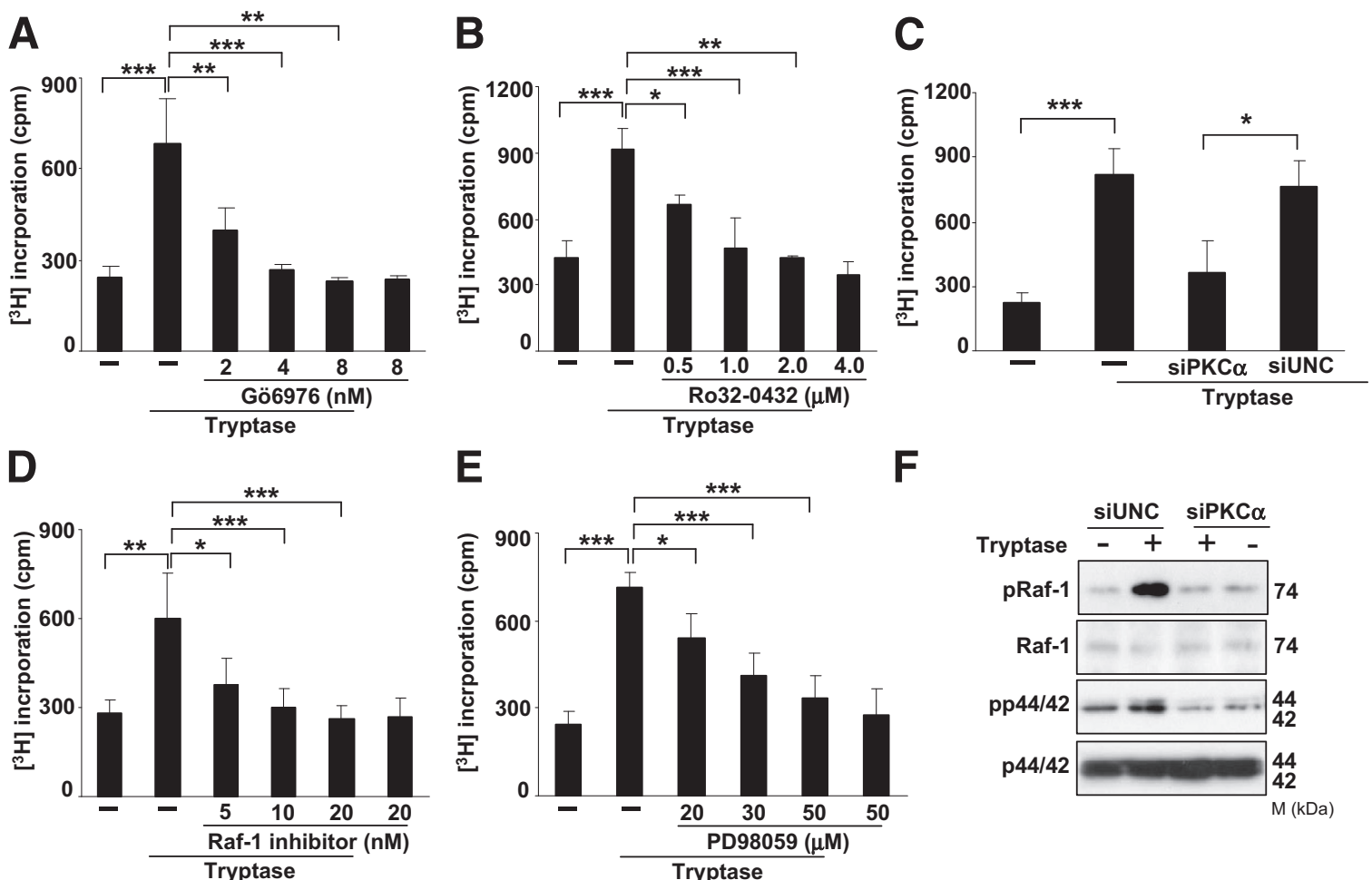

Figure 5 Tryptase-induced proliferation of HLFs is PKC- $\alpha /$ Raf- $1 /$ p44/42 dependent. Cell proliferation was assessed by $\left[{ }^{3} \mathrm{H}\right]$ thymidine incorporation. A and B: Proliferation of control HLFs pretreated with the PKC- $\alpha / \beta$ inhibitor Gö 6976 (A) or the PKC- $\alpha$ inhibitor Ro $32-0432$ (B) in response to $2 \mathrm{nmol} / \mathrm{L}$ tryptase. C: Effect of PKC- $\alpha$ knockdown on $2 \mathrm{nmol} / \mathrm{L}$ tryptase-induced proliferation of HLFs. D and E: Proliferation of HLFs pretreated with Raf-1 inhibitor (D) or the MEK1/ 2/p44/42 inhibitor PD 98059 (E) in response to $2 \mathrm{nmol} / \mathrm{L}$ tryptase. F: Activation of Raf-1 and p44/42 in response to $2 \mathrm{nmol} / \mathrm{L}$ tryptase in PKC- $\alpha$ depleted HLFs. Data are expressed as means \pm SD from three $(\mathbf{F})$, four $(\mathbf{C}-\mathbf{E})$, or five $(\mathbf{A}$ and $\mathbf{B})$ independent experiments. ${ }^{*} P<0.05,{ }^{* *} P<0.01$, and ${ }^{* * *} P<0.001$.

the surface of MCs, thereby inducing MC survival and proliferation.

\section{Discussion}

A growing body of evidence suggests that MCs may participate in fibrotic processes. Diseases in which MCs are thought to be involved, such as chronic allergic asthma and systemic mastocytosis, demonstrate fibrotic changes in various organs. In chronic allergic asthma, MCs are supposed to contribute to structural changes of the airway wall, including abnormal subepithelial deposition of collagen and other extracellular matrix proteins. ${ }^{34}$ In systemic mastocytosis, fibrotic changes have been found in bone marrow, liver, spleen, and skin. ${ }^{35}$ Furthermore, previous publications demonstrated elevated numbers of MCs in association with renal interstitial fibrosis, ${ }^{9-11}$ liver cirrhosis, ${ }^{12}$ pancreatic fibrosis, ${ }^{36}$ and fibrotic lung diseases (including IPF) ${ }^{17-19}$ Consistent with these findings, we also noted an increased number of MCs and an elevated level of tryptase in the lung parenchyma of IPF patients. The majority of MCs present in IPF lung tissue was degranulated, indicating that they underwent activation. Potentiated activation of MCs was also observed on their incubation with BALF obtained from IPF patients, compared with BALF derived from healthy control subjects.
Many potential mediators could be responsible for MC degranulation in the fibrotic lung. For example, factors such as substance $\mathrm{P},{ }^{37} \mathrm{IL}-8,{ }^{38,39} \mathrm{MIP}-1 \alpha,{ }^{40} \mathrm{TNF}-\alpha,{ }^{41}$ endothelin$1,{ }^{42}$ GM-CSF, ${ }^{43}$ and immunoglobulin free light chains ${ }^{44}$ have been found to be elevated in IPF lungs and are known MC activators. In addition, it is conceivable that MCs undergo activation in the lungs of IPF patients in response to ongoing infection. Respiratory/pulmonary infections are thought to be important (secondary) trigger factors for the initiation and/or progression/exacerbation of pulmonary fibrosis. ${ }^{45-48}$ Consistent with these considerations, human MC degranulation has been observed in response to bacterial and viral products, ${ }^{49,50}$ complement components, ${ }^{51}$ and on activation of FceRI, Fc $\gamma$ RI, ${ }^{52}$ and Toll-like receptors 2 and $4 .{ }^{53} \mathrm{We}$ believe that comprehensive further studies in this field are required to exactly identify the mediator or mediators that in fact drive MC degranulation in the fibrotic lung. Our present data, however, indicate that HLFs are important but probably not the only regulators of $\mathrm{MC}$ degranulation in the (diseased) lung. We found that MCs become degranulated in the presence of HLFs, as demonstrated by the release of tryptase into the cell-culture medium, suggesting that HLFs produce one or more soluble mediators that are able to regulate MC function. Of importance, we observed only a partial activation of MCs in the presence of HLFs, as evinced by 
A

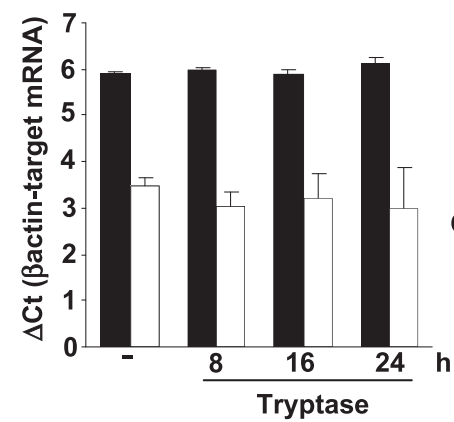

D

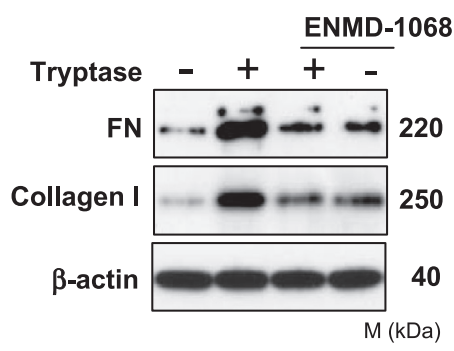

G

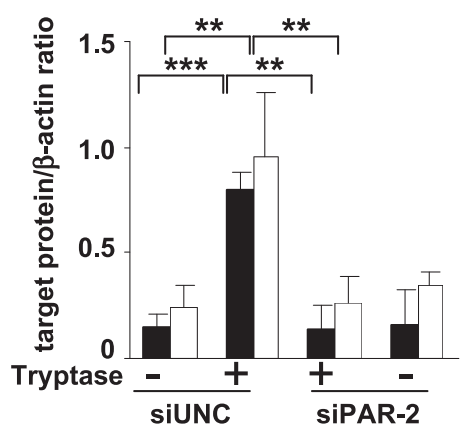

B

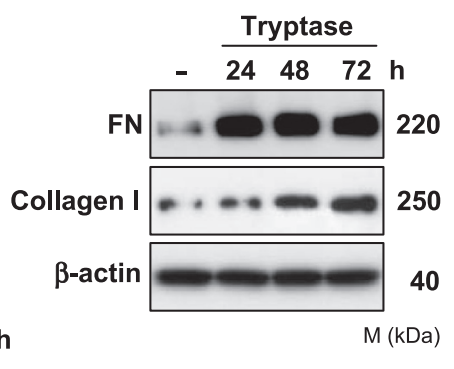

E

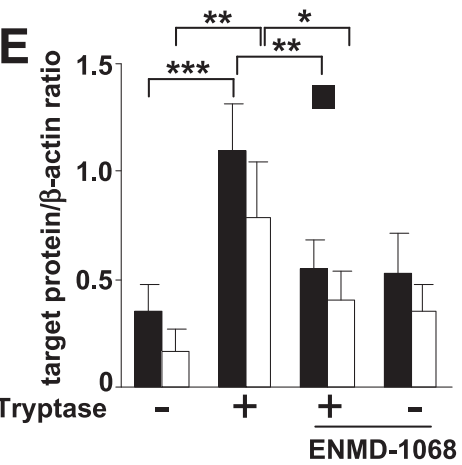

H

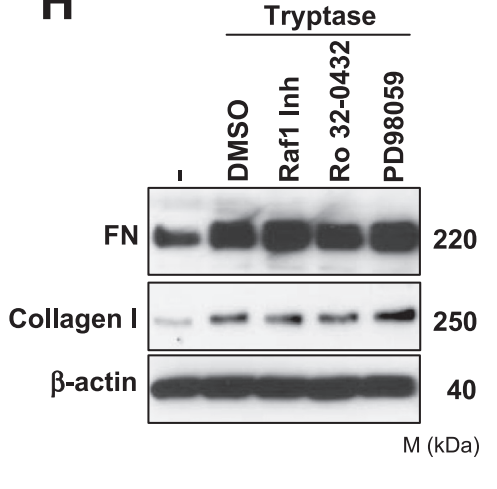

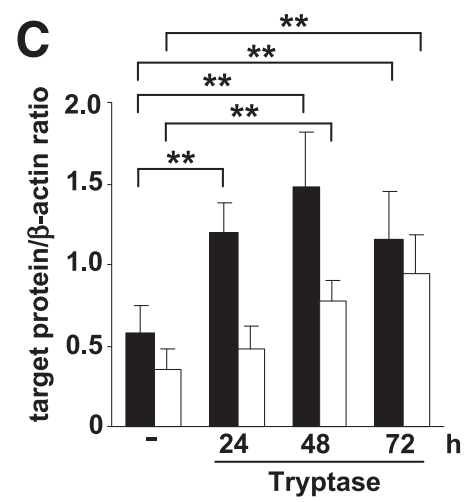

$\mathbf{F}$

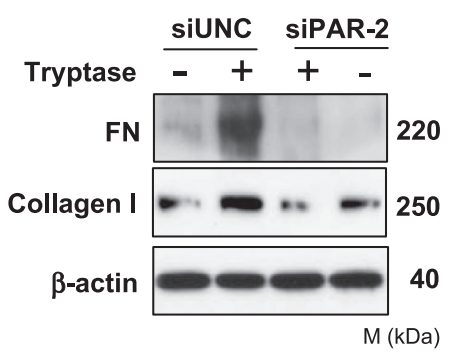

I

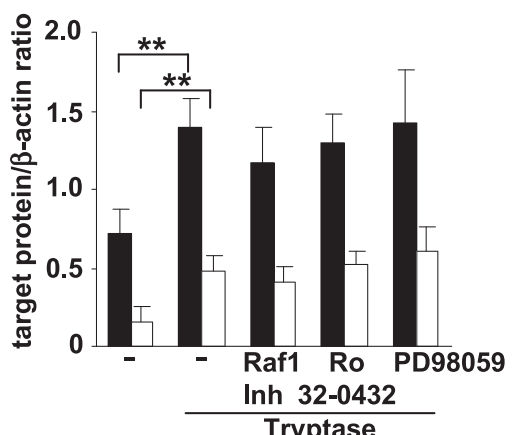

Figure 6 Tryptase-induced synthesis of FN (black bars) and collagen I (white bars) in HLFs does not involve the PKC- $\alpha /$ Raf-1/p44/42 signaling pathway. A and B: Time course of FN and collagen I expression in control HLFs after $2 \mathrm{nmol} / \mathrm{L}$ tryptase stimulation as assessed by RT-qPCR (A) and Western blotting (B). RT-qPCR results are expressed as $\Delta C_{T}$, with $\beta$-actin as the reference gene. Blots are from one representative experiment out of four. C: Densitometric analysis of data in panel B. D: FN and collagen I expression in HLFs pretreated with $50 \mu \mathrm{g} / \mathrm{mL}$ of the PAR-2 antagonist ENMD-1068 for 1 hour before exposure to $2 \mathrm{nmol} / \mathrm{L}$ tryptase. E: Densitometric analysis of data in panel D. F: Effect of PAR-2 knockdown on $2 \mathrm{nmol} / \mathrm{L}$ tryptase-induced FN and collagen I expression. Blots are from one representative experiment out of four. G: Densitometric analysis of data in panel $\mathbf{F}$. H: Effect of $10 \mathrm{nmol} / \mathrm{L}$ Raf-1 inhibitor, $1 \mu \mathrm{mol} / \mathrm{L}$ Ro $32-0432$ (PKC- $\alpha$ inhibitor), or $30 \mu \mathrm{mol} / \mathrm{L}$ PD 98059 (MEK1/2/p44/42 inhibitor) on $2 \mathrm{nmol} / \mathrm{L}$ tryptase-stimulated FN and collagen I synthesis in HLFs. DMS0, dimethyl sulfoxide. I: Densitometric analysis of data in panel H. $n=3$ (I) or $4(\mathbf{A}, \mathbf{C}, \mathbf{E}$, and $\mathbf{G}) .{ }^{*} P<0.05,{ }^{*} P<0.01$, and ${ }^{* *} P<0.001$.

further increase in tryptase release when the compound C48/ 89 was added. This suggests that mediators from other cell types might also contribute to MC activation in the lung. This might be particularly true for the diseased/fibrotic lung. These considerations are supported by our data showing that the extent of MC activation did not significantly differ between donor and IPF HLFs, as evinced by similar amounts of released tryptase, although degranulated MCs were predominately observed in the lungs of IPF patients compared with control subjects, and although potentiated degranulation of MCs was noted on their incubation with
BALF obtained from IPF patients, compared with BALF derived from healthy control subjects.

Activation of MCs leads to the release of a variety of mediators accumulated within their granules, and among these tryptase is the most abundant. In addition, the fact that tryptase-positive $\mathrm{MCs}$ are the dominant $\mathrm{MC}$ type in the human peripheral lung, and particularly also in the diseased/ fibrotic lung (Figure 1), prompted us to focus our further studies on the intracellular signaling pathway mediating mitogenic activities of tryptase toward HLFs. Coculture of HLFs with MCs stimulated release of tryptase, which in turn 
induced HLF proliferation. The importance of MC degranulation in general and of tryptase release in particular in this respect is emphasized by our findings that i) proliferation of HLFs induced by activated MCs was significantly attenuated in the presence of the tryptase inhibitor APC 366, ii) purified
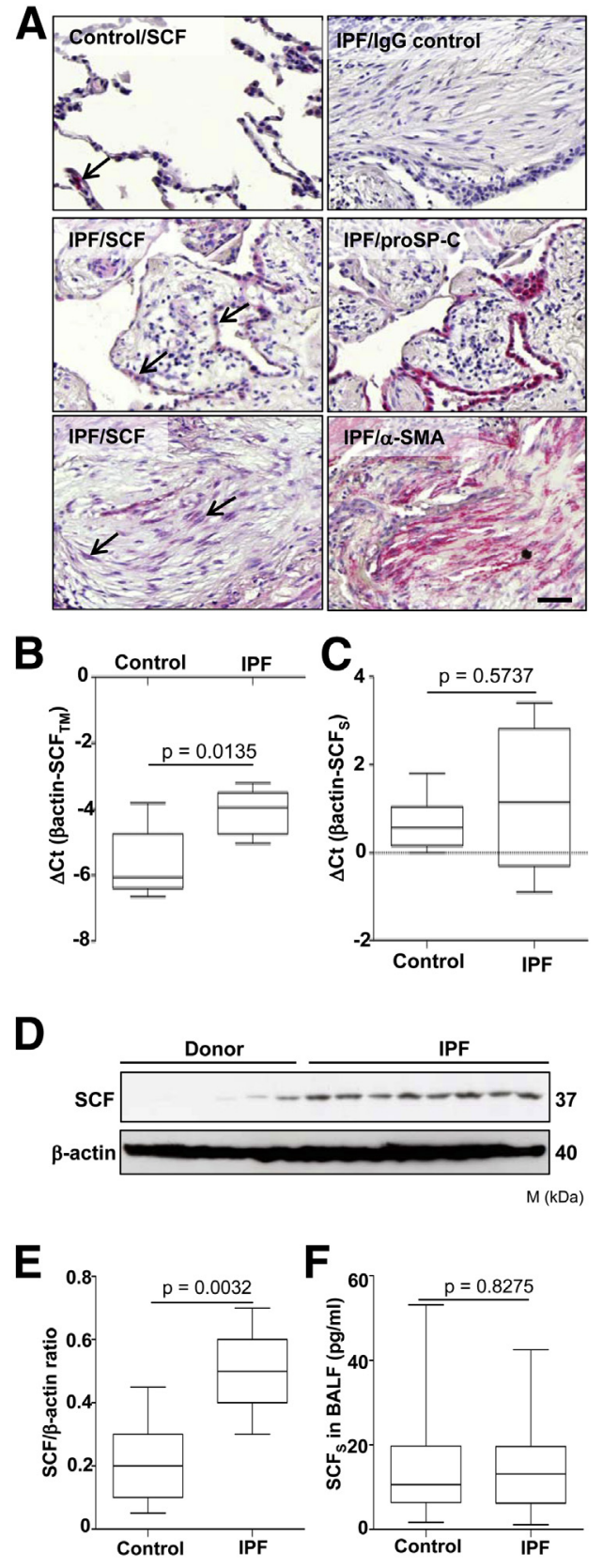

G

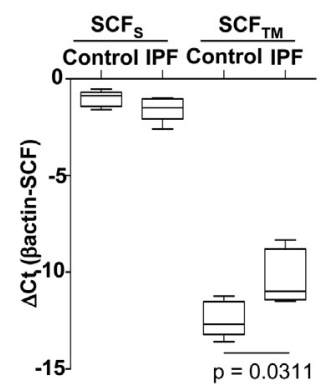

tryptase induced HLF proliferation in a dose-dependent manner, and iii) addition of C48/80 to MCs further increased their proproliferative activities toward cocultured fibroblasts, both from control subjects and IPF patients.

Although the present findings suggest that tryptase is an important substance that, upon MC activation, induces lung fibroblast proliferation, other MC-derived mediators might be involved in this process as well. This consideration is supported by our finding that the tryptase inhibitor APC366 was not able to entirely reverse MC-triggered mitogenic activities toward fibroblasts, not even at high concentrations, and also by previous studies demonstrating proproliferative activities of other MC-derived molecules, such as chymase, histamine, PDGF, and TGF- $\beta 1 .^{22}$ Moreover, although the amount of released tryptase from MCs did not differ between donor and IPF HLFs, the IPF HLFs displayed a significantly more enhanced proliferation rate, compared with donor fibroblasts, on coincubation with MCs; this finding suggests the possibility that upon the impact of fibrotic but not control lung fibroblasts profibrotic mediators other than tryptase are newly synthesized and/or preferentially released by activated MCs have an effect on fibrotic but not control HLFs. Another possible explanation for this observation is that IPF HLFs could be sensitized to profibrotic cellular effects induced by MC-derived tryptase (or other mediators). Consistent with this notion, increased expression levels of PAR-2, a receptor for tryptase, were recently found in IPF HLFs. ${ }^{26}$ Thus, by modulating the expression of the particular receptors, fibroblasts could regulate the degree of their response to MCderived ligands. The central role of PAR-2 in tryptaseinduced lung fibroblast proliferation is emphasized by our experiments demonstrating that this process was inhibited in the presence of the PAR-2-specific antagonist ENMD-1068 or when PAR-2-depleted cells were used. Here, it is noteworthy, that MC-derived tryptase not only potentiated HLF proliferation but also induced expression of FN and collagen I (two extracellular matrix proteins that are known to be upregulated in IPF lungs) in a PAR-2-dependent manner. Taken together, these findings are consistent with previous observations showing that PAR-2 is an important mediator of various tryptase-induced cellular effects in different cell populations. $^{30,54,55}$

\footnotetext{
Figure 7 Expression of $\mathrm{SCF}_{\mathrm{TM}}$ is elevated in the lungs of IPF patients. A: Representative serial lung sections from IPF patients (1/10) and control subjects $(1 / 5)$ stained for SCF, pro-SPC, or $\alpha$-SMA. Negative IgG isotype control is included. SCF-positive cells are indicated by arrows. B and C: Expression of the transmembrane (B) and soluble (C) forms of SCF in lung homogenates of control subjects $(n=10)$ and IPF patients $(n=24)$ as assessed by RT-qPCR; $\beta$-actin was used as the reference gene. D: SCF expression in lung homogenates of representative donors $(6 / 10)$ and IPF patients (8/24) as assessed by Western blotting. E: Densitometric analysis of data in panel $\mathbf{D}$. F: Quantification of $\mathrm{SCF}_{\mathrm{S}}$ antigen level in BALF samples from IPF patients $(n=40)$ and healthy control subjects $(n=20)$. G: Expression of transmembrane and soluble forms of SCF in fibroblasts isolated from control $(n=5)$ and IPF $(n=5)$ lungs as assessed by RT-qPCR, with $\beta$-actin as the reference gene. Data are expressed as box-and-whisker plots (defined under Statistical Analysis). Scale bar $=50 \mu \mathrm{m}$.
} 

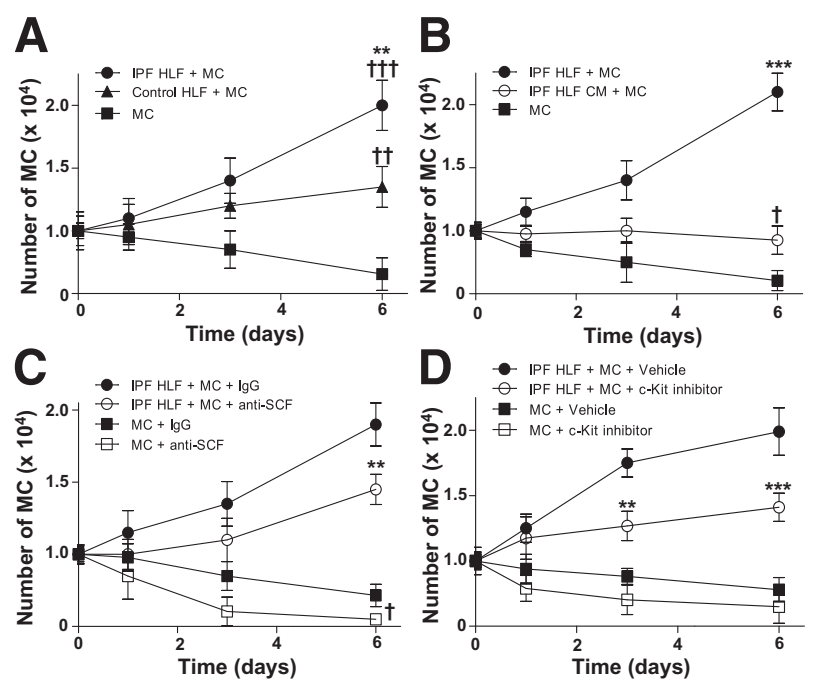

Figure 8 IPF HLF-induced MC survival and proliferation are dependent on both $\mathrm{SCF}_{\mathrm{TM}}$ and c-Kit. A: Number of MCs present over 6 days of coculture with fibroblasts isolated from IPF (IPF HLF) or control (control HLF) lungs. B: Number of MCs present over 6 days of culture with IPF HLFs or in IPF HLF-conditioned medium (IPF HLF CM). C: Number of MCs present over 6 days of coculture with IPF HLFs in the presence of anti-human SCF neutralizing antibody or isotype IgG control. D: Number of MCs present over 6 days of coculture with IPF HLFs in the presence of c-Kit inhibitor. Data are expressed as means \pm SD from three (D), four (B and $\mathbf{C}$ ), or five (A) independent experiments, each performed in triplicate. ${ }^{* *} P<0.01$ versus control HLF+MC; ${ }^{\dagger \dagger} P<0.01 ;{ }^{\dagger \dagger} P<0.001$ versus MC (A). ${ }^{* * *} P<0.001$ versus IPF HLF CM+MC; ${ }^{\dagger} P<0.05$ versus MC (B). ${ }^{* *} P<0.01$ versus IPF $\mathrm{HLF}+\mathrm{MC}+\mathrm{IgG} ;{ }^{\dagger} P<0.05$ versus $\mathrm{MC}+\mathrm{IgG}(\mathrm{C}) .{ }^{* *} P<0.01,{ }^{* *} P<0.001$ versus IPF HLF+MC+Vehicle (D).

Along with its induction of fibroblast proliferation and ECM production, MC-derived tryptase might contribute to the pathogenesis of lung fibrosis also via other mechanisms. For example, tryptase was shown to stimulate fibroblast chemotaxis $^{56}$ and to modulate the release of cytokines, chemokines and growth factors from fibroblasts and other cells types. ${ }^{57,58}$ Additionally, tryptase (either alone or in conjunction with activated matrix metalloproteinases) may participate in ECM degradation processes, including destruction of basement membrane. ${ }^{24}$ Furthermore, tryptase could be involved in myofibroblast differentiation, as previously suggested. ${ }^{59,60}$ However, we found that MC-derived tryptase does not induce differentiation of HLFs to a myofibroblast phenotype. Differences in the tissue origin of the fibroblasts used in the different studies might explain the discrepancies.

Next, we demonstrated that tryptase triggers mitogenic activities in HLFs in a PKC- $\alpha /$ Raf-1/p44/42-dependent manner. The role of different members of the PKC family in the development of fibrosis has been reported in various organs, including the liver and the lung. In this context, TGF$\beta 1$ was found to regulate collagen synthesis in pulmonary fibroblasts not only via a Smad3/4-dependent signaling pathway, but also through $\mathrm{PKC}-\delta,{ }^{61}$ whereas thrombin profibrotic activities (including induction of fibroblast differentiation, resistance to apoptosis, and collagen expression) were shown to be PKC- $\varepsilon$ dependent. ${ }^{62}$ Furthermore, a central role of PKC- $\alpha$ in CCL18-driven collagen production in lung fibroblasts has recently been described. ${ }^{63}$ We have built upon these findings and demonstrated for the first time that tryptase-stimulated HLF proliferation is PKC- $\alpha / \mathrm{Raf}-1 / \mathrm{p} 44 /$ 42 mediated. Taken together, these findings suggest that distinct PKC isoforms expressed in fibroblasts are activated in response to a variety of stimuli and drive fibrogenic processes. In support of the potential clinical relevance of our observation, we have also demonstrated prominent immunoreactivity for PKC- $\alpha$ and activated p44/42 in fibroblasts/ myofibroblasts of fibroblastic foci in IPF lungs (unpublished data). The present in vitro results showing that inhibition of PKC- $\alpha$, Raf- 1 , or $\mathrm{p} 44 / 42$, as well as PKC- $\alpha$ knockdown, diminishes tryptase-induced mitogenic activities toward HLFs, suggest that interference with this pathway could be of potential therapeutic benefit in lung fibrosis. Future in vivo studies applying PKC inhibitors in animal models of lung fibrosis may identify novel potential targets for the treatment of human patients with pulmonary fibrosis.

Our final experiments (Figure 8) indicated that fibroblasts seemingly do not only contribute to MC activation/degranulation, as discussed above, but seem also to regulate other MC properties that could contribute to the MC hyperplasia observed in fibrotic regions of IPF lungs. Coculture of MCs with HLFs potentiated MC proliferation, and this effect was very prominent when fibroblasts isolated from IPF lungs were used. Moreover, the $\mathrm{SCF}_{\mathrm{TM}}$ form (which is displayed on HLFs) and the c-Kit receptor on the surface of MCs were found, in part, to be responsible for IPF HLF-induced MC hyperplasia. The fact that the fibroblast-derived $\mathrm{SCF}_{\mathrm{TM}}$ (but not $\mathrm{SCF}_{\mathrm{S}}$ ) drives $\mathrm{MC}$ proliferation implies that these two cell populations have to be in close proximity to each other. Indeed, in IPF lung tissue, MCs were localized near fibroblastic foci, suggesting that a close and mutual relationship between MCs and fibroblasts exists in IPF lungs. In this relationship, fibroblasts could promote MC survival, proliferation, and activation, whereas mediators released from MCs could stimulate mitogenic activities toward fibroblasts and ECM production by these cells. Altogether, this could lead to progression of lung fibrosis. Further studies are required to explore the detailed mechanisms of fibroblastinduced MC survival/proliferation in the fibrotic lung. Based on previous reports, this mechanism may involve cell adhesion molecule 1 protein (CADM1). ${ }^{64,65}$ CADM1 was recently shown to regulate proliferation of human lung MCs by facilitating the interaction between membrane-bound SCF expressed on airway smooth-muscle cells and human lung MC c-Kit. ${ }^{65}$ Furthermore, it is possible that CADM1 modulates MC proliferation via a c-Kit-independent mechanism (eg, by interacting with its own counter-receptor on the HLF cell surface). Moreover, fibroblast-derived mediators such as IL-6, IL-10, or nerve growth factor may also contribute to potentiated MC growth. ${ }^{66}$

In conclusion, here we have demonstrated the presence of a positive feedback loop between fibroblasts and MCs in the 
fibrotic lung: $\mathrm{SCF}_{\mathrm{TM}}$ produced by IPF HLFs promotes $\mathrm{MC}$ proliferation, and tryptase released from MC cells stimulates fibroblast growth in a PAR-2/PKC- $\alpha / \mathrm{p} 44 / 42-$ dependent manner and stimulates FN and collagen I synthesis independently of PKC- $\alpha$, Raf-1, and p44/42 activities. Targeting the main players in this signaling cascade may open new therapeutical perspectives for the treatment of IPF.

\section{Acknowledgments}

We thank Horst Thiele, Yvonne Horn, and Ewa Bieniek for their excellent technical assistance and Walter Klepetko (University of Vienna) for kindly providing human lung tissue.

\section{Supplemental Data}

Supplemental material for this article can be found at http://dx.doi.org/10.1016/j.ajpath.2013.02.013.

\section{References}

1. Brown JM, Wilson TM, Metcalfe DD: The mast cell and allergic diseases: role in pathogenesis and implications for therapy. Clin Exp Allergy 2008, 38:4-18

2. Marshall JS: Mast-cell responses to pathogens. Nat Rev Immunol 2004, 4:787-799

3. Metcalfe DD, Baram D, Mekori YA: Mast cells. Physiol Rev 1997, 77:1033-1079

4. Malaviya R, Abraham SN: Role of mast cell leukotrienes in neutrophil recruitment and bacterial clearance in infectious peritonitis. $\mathrm{J}$ Leukoc Biol 2000, 67:841-846

5. Tani K, Ogushi F, Kido H, Kawano T, Kunori Y, Kamimura T, Cui P, Sone S: Chymase is a potent chemoattractant for human monocytes and neutrophils. J Leukoc Biol 2000, 67:585-589

6. Rajakulasingam K, Hamid Q, O'Brien F, Shotman E, Jose PJ, Williams TJ, Jacobson M, Barkans J, Durham SR: RANTES in human allergen-induced rhinitis: cellular source and relation to tissue eosinophilia. Am J Respir Crit Care Med 1997, 155:696-703

7. Aceves SS, Chen D, Newbury RO, Dohil R, Bastian JF, Broide DH: Mast cells infiltrate the esophageal smooth muscle in patients with eosinophilic esophagitis, express TGF-betal, and increase esophageal smooth muscle contraction. J Allergy Clin Immunol 2010, 126: 1198-1204.e4

8. Levi-Schaffer F, Rubinchik E: Activated mast cells are fibrogenic for 3 T3 fibroblasts. J Invest Dermatol 1995, 104:999-1003

9. Tóth T, Tóth-Jakatics R, Jimi S, Takebayashi S: Increased density of interstitial mast cells in amyloid A renal amyloidosis. Mod Pathol 2000, 13:1020-1028

10. Kondo S, Kagami S, Kido H, Strutz F, Müller GA, Kuroda Y: Role of mast cell tryptase in renal interstitial fibrosis. J Am Soc Nephrol 2001, 12:1668-1676

11. Hiromura K, Kurosawa M, Yano S, Naruse T: Tubulointerstitial mast cell infiltration in glomerulonephritis. Am J Kidney Dis 1998, 32: 593-599

12. Yamashiro M, Kouda W, Kono N, Tsuneyama K, Matsui O, Nakanuma Y: Distribution of intrahepatic mast cells in various hepatobiliary disorders. An immunohistochemical study. Virchows Arch 1998, 433:471-479

13. Skopouli FN, Li L, Boumba D, Stefanaki S, Hanel K, Moutsopoulos HM, Krilis SA: Association of mast cells with fibrosis and fatty infiltration in the minor salivary glands of patients with Sjögren's syndrome. Clin Exp Rheumatol 1998, 16:63-65

14. Ohrn MB, Sköld CM, van Hage-Hamsten M, Sigurdardottir O, Zetterström O, Eklund A: Sarcoidosis patients have bronchial hyperreactivity and signs of mast cell activation in their bronchoalveolar lavage. Respiration 1995, 62:136-142

15. Schildge J, Klar B, Hardung-Backes M: Die Mastzelle in der bronchoalveolären Lavage bei interstitiellen Lungenerkrankungen: [Mast cells in bronchoalveolar lavage fluid of patients with interstitial lung diseases]. German. Pneumologie 2003, 57:202-207

16. Hamada H, Vallyathan V, Cool CD, Barker E, Inoue Y, Newman LS: Mast cell basic fibroblast growth factor in silicosis. Am J Respir Crit Care Med 2000, 161:2026-2034

17. Hunt LW, Colby TV, Weiler DA, Sur S, Butterfield JH: Immunofluorescent staining for mast cells in idiopathic pulmonary fibrosis: quantification and evidence for extracellular release of mast cell tryptase. Mayo Clin Proc 1992, 67:941-948

18. Cha SI, Chang CS, Kim EK, Lee JW, Matthay MA, Golden JA, Elicker BM, Jones K, Collard HR, Wolters PJ: Lung mast cell density defines a subpopulation of patients with idiopathic pulmonary fibrosis. Histopathology 2012, 61:98-106

19. Andersson CK, Andersson-Sjöland A, Mori M, Hallgren O, Pardo A, Eriksson L, Bjermer L, Löfdahl CG, Selman M, WestergrenThorsson G, Erjefält JS: Activated MCTC mast cells infiltrate diseased lung areas in cystic fibrosis and idiopathic pulmonary fibrosis. Respir Res 2012, 12:139

20. Kawatani K, Kondo M, Tamaoki J, Tagaya E, Nagai A: [The clinical significance of mast cell tryptase in bronchial alveolar lavage fluid in interstitial lung diseases]. Japanese. Nihon Kokyuki Gakkai Zasshi 2007, 45:848-855

21. McLarty JL, Meléndez GC, Brower GL, Janicki JS, Levick SP: Tryptase/Protease-activated receptor 2 interactions induce selective mitogen-activated protein kinase signaling and collagen synthesis by cardiac fibroblasts. Hypertension 2011, 58:264-270

22. Hetzel M, Bachem M, Anders D, Trischler G, Faehling M: Different effects of growth factors on proliferation and matrix production of normal and fibrotic human lung fibroblasts. Lung 2005, 183:225-237

23. Tchougounova E, Lundequist A, Fajardo I, Winberg JO, Abrink M, Pejler G: A key role for mast cell chymase in the activation of promatrix metalloprotease-9 and pro-matrix metalloprotease-2. J Biol Chem 2005, 280:9291-9296

24. Iddamalgoda A, Le QT, Ito K, Tanaka K, Kojima H, Kido H: Mast cell tryptase and photoaging: possible involvement in the degradation of extra cellular matrix and basement membrane proteins. Arch Dermatol Res 2008, 300(Suppl 1):S69-S76

25. Raghu G, Collard HR, Egan JJ, Martinez FJ, Behr J, Brown KK, Colby TV, Cordier JF, Flaherty KR, Lasky JA, Lynch DA, Ryu JH, Swigris JJ, Wells Ancochea J, Bouros D, Carvalho C, Costabel U, Ebina M, Hansell DM, Johkoh T, Kim DS, King TE Jr, Kondoh Y, Myers J, Müller NL, Nicholson AG, Richeldi L, Selman M, Dudden RF, Griss BS, Protzko SL, Schünemann HJ; ATS/ERS/JRS/ALAT Committee on Idiopathic Pulmonary Fibrosis: An official ATS/ERS/JRS/ALAT statement: idiopathic pulmonary fibrosis: evidence-based guidelines for diagnosis and management. Am J Respir Crit Care Med 2011, 183:788-824

26. Wygrecka M, Kwapiszewska G, Jablonska E, von Gerlach S, Henneke I, Zakrzewicz D, Guenther A, Preissner KT, Markart P: Role of protease-activated receptor-2 in idiopathic pulmonary fibrosis. Am J Respir Crit Care Med 2011, 183:1703-1714

27. Jablonska E, Markart P, Zakrzewicz D, Preissner KT, Wygrecka M: Transforming growth factor-beta1 induces expression of human coagulation factor XII via Smad3 and JNK signaling pathways in human lung fibroblasts. J Biol Chem 2010, 285:11638-11651

28. Wygrecka M, Wilhelm J, Jablonska E, Zakrzewicz D, Preissner KT, Seeger W, Guenther A, Markart P: Shedding of low-density lipoprotein receptor-related protein-1 in acute respiratory distress syndrome. Am J Respir Crit Care Med 2011, 184:438-448 
29. Dahal BK, Kosanovic D, Kaulen C, Cornitescu T, Savai R, Hoffmann J, Reiss I, Ghofrani HA, Weissmann N, Kuebler WM, Seeger W, Grimminger F, Schermuly RT: Involvement of mast cells in monocrotaline-induced pulmonary hypertension in rats. Respir Res 2011, 12:60

30. Akers IA, Parsons M, Hill MR, Hollenberg MD, Sanjar S, Laurent GJ, McAnulty RJ: Mast cell tryptase stimulates human lung fibroblast proliferation via protease-activated receptor-2. Am J Physiol Lung Cell Mol Physiol 2000, 278:L193-L201

31. Choi SW, Park HY, Rubeiz NG, Sachs D, Gilchrest BA: Protein kinase C-alpha levels are inversely associated with growth rate in cultured human dermal fibroblasts. J Dermatol Sci 1998, 18: 54-63

32. Racchi M, Bergamaschi S, Govoni S, Wetsel WC, Bianchetti A, Binetti G, Battaini F, Trabucchi M: Characterization and distribution of protein kinase $\mathrm{C}$ isoforms in human skin fibroblasts. Arch Biochem Biophys 1994, 314:107-111

33. Broudy VC: Stem cell factor and hematopoiesis. Blood 1997, 90: 1345-1364

34. Brewster CE, Howarth PH, Djukanovic R, Wilson J, Holgate ST, Roche WR: Myofibroblasts and subepithelial fibrosis in bronchial asthma. Am J Respir Cell Mol Biol 1990, 3:507-511

35. Horny HP, Parwaresch MR, Lennert K: Bone marrow findings in systemic mastocytosis. Hum Pathol 1985, 16:808-814

36. Zimnoch L, Szynaka B, Puchalski Z: Mast cells and pancreatic stellate cells in chronic pancreatitis with differently intensified fibrosis. Hepatogastroenterology 2002, 49:1135-1138

37. Takeyama M, Nagai S, Mori K, Ikawa K, Satake N, Izumi T: Substance P-like immunoreactive substance in bronchoalveolar lavage fluids from patients with idiopathic pulmonary fibrosis and pulmonary sarcoidosis. Sarcoidosis Vasc Diffuse Lung Dis 1996, 13: $33-37$

38. Ziegenhagen MW, Zabel P, Zissel G, Schlaak M, MüllerQuernheim J: Serum level of interleukin 8 is elevated in idiopathic pulmonary fibrosis and indicates disease activity. Am J Respir Crit Care Med 1998, 157:762-768

39. Carré PC, Mortenson RL, King TE Jr, Noble PW, Sable CL, Riches DW: Increased expression of the interleukin-8 gene by alveolar macrophages in idiopathic pulmonary fibrosis. A potential mechanism for the recruitment and activation of neutrophils in lung fibrosis. J Clin Invest 1991, 88:1802-1810

40. Standiford TJ, Rolfe MW, Kunkel SL, Lynch JP 3rd, Burdick MD, Gilbert AR, Orringer MB, Whyte RI, Strieter RM: Macrophage inflammatory protein-1 alpha expression in interstitial lung disease. J Immunol 1993, 151:2852-2863

41. Zhang Y, Lee TC, Guillemin B, Yu MC, Rom WN: Enhanced IL-1 beta and tumor necrosis factor-alpha release and messenger RNA expression in macrophages from idiopathic pulmonary fibrosis or after asbestos exposure. J Immunol 1993, 150:4188-4196

42. Saleh D, Furukawa K, Tsao MS, Maghazachi A, Corrin B, Yanagisawa M, Barnes PJ, Giaid A: Elevated expression of endothelin-1 and endothelin-converting enzyme-1 in idiopathic pulmonary fibrosis: possible involvement of proinflammatory cytokines. Am J Respir Cell Mol Biol 1997, 16:187-193

43. Walker C, Bauer W, Braun RK, Menz G, Braun P, Schwarz F, Hansel TT, Villiger B: Activated T cells and cytokines in bronchoalveolar lavages from patients with various lung diseases associated with eosinophilia. Am J Respir Crit Care Med 1994, 150: $1038-1048$

44. Groot Kormelink T, Pardo A, Knipping K, Buendía-Roldán I, Garcíade-Alba C, Blokhuis BR, Selman M, Redegeld FA: Immunoglobulin free light chains are increased in hypersensitivity pneumonitis and idiopathic pulmonary fibrosis. PLoS One 2011, 6:e25392

45. Lok SS, Haider Y, Howell D, Stewart JP, Hasleton PS, Egan JJ: Murine gammaherpes virus as a cofactor in the development of pulmonary fibrosis in bleomycin resistant mice. Eur Respir J 2002, $20: 1228-1232$
46. Mora AL, Woods CR, Garcia A, Xu J, Rojas M, Speck SH, Roman J, Brigham KL, Stecenko AA: Lung infection with gamma-herpesvirus induces progressive pulmonary fibrosis in Th2-biased mice. Am J Physiol Lung Cell Mol Physiol 2005, 289:L711-L721

47. Stewart JP, Egan JJ, Ross AJ, Kelly BG, Lok SS, Hasleton PS, Woodcock AA: The detection of Epstein-Barr virus DNA in lung tissue from patients with idiopathic pulmonary fibrosis. Am J Respir Crit Care Med 1999, 159:1336-1341

48. McMillan TR, Moore BB, Weinberg JB, Vannella KM, Fields WB, Christensen PJ, van Dyk LF, Toews GB: Exacerbation of established pulmonary fibrosis in a murine model by gammaherpesvirus. Am J Respir Crit Care Med 2008, 177:771-780

49. Malaviya R, Gao Z, Thankavel K, van der Merwe PA, Abraham SN: The mast cell tumor necrosis factor alpha response to FimH-expressing Escherichia coli is mediated by the glycosylphosphatidylinositolanchored molecule CD48. Proc Natl Acad Sci USA 1999, 96: 8110-8115

50. Patella V, Florio G, Petraroli A, Marone G: HIV-1 gp120 induces IL-4 and IL-13 release from human Fc epsilon RI+ cells through interaction with the VH3 region of IgE. J Immunol 2000, 164: 589-595

51. Nilsson G, Johnell M, Hammer $\mathrm{CH}$, Tiffany HL, Nilsson $\mathrm{K}$, Metcalfe DD, Siegbahn A, Murphy PM: C3a and C5a are chemotaxins for human mast cells and act through distinct receptors via a pertussis toxin-sensitive signal transduction pathway. J Immunol 1996, 157:1693-1698

52. Genovese A, Bouvet JP, Florio G, Lamparter-Schummert B, Björck L, Marone G: Bacterial immunoglobulin superantigen proteins $\mathrm{A}$ and $\mathrm{L}$ activate human heart mast cells by interacting with immunoglobulin E. Infect Immun 2000, 68:5517-5524

53. Varadaradjalou S, Féger F, Thieblemont N, Hamouda NB, Pleau JM, Dy M, Arock M: Toll-like receptor 2 (TLR2) and TLR4 differentially activate human mast cells. Eur J Immunol 2003, 33:899-906

54. Schechter NM, Brass LF, Lavker RM, Jensen PJ: Reaction of mast cell proteases tryptase and chymase with protease activated receptors (PARs) on keratinocytes and fibroblasts. J Cell Physiol 1998, 176: 365-373

55. Duchesne E, Tremblay MH, Côté $\mathrm{CH}$ : Mast cell tryptase stimulates myoblast proliferation; a mechanism relying on protease-activated receptor-2 and cyclooxygenase-2. BMC Musculoskelet Disord 2011, 12:235

56. Gruber BL, Kew RR, Jelaska A, Marchese MJ, Garlick J, Ren S, Schwartz LB, Korn JH: Human mast cells activate fibroblasts: tryptase is a fibrogenic factor stimulating collagen messenger ribonucleic acid synthesis and fibroblast chemotaxis. J Immunol 1997, 158: 2310-2317

57. Shin K, Nigrovic PA, Crish J, Boilard E, McNeil HP, Larabee KS, Adachi R, Gurish MF, Gobezie R, Stevens RL, Lee DM: Mast cells contribute to autoimmune inflammatory arthritis via their tryptase/ heparin complexes. J Immunol 2009, 182:647-656

58. Namazi MR: Possible molecular mechanisms to account for the involvement of tryptase in the pathogenesis of psoriasis. Autoimmunity 2005, 38:449-452

59. Gailit J, Marchese MJ, Kew RR, Gruber BL: The differentiation and function of myofibroblasts is regulated by mast cell mediators. J Invest Dermatol 2001, 117:1113-1119

60. Mangia A, Malfettone A, Rossi R, Paradiso A, Ranieri G, Simone G, Resta L: Tissue remodelling in breast cancer: human mast cell tryptase as an initiator of myofibroblast differentiation. Histopathology 2011, 58:1096-1106

61. Zhang L, Keane MP, Zhu LX, Sharma S, Rozengurt E, Strieter RM, Dubinett SM, Huang M: Interleukin-7 and transforming growth factor-beta play counter-regulatory roles in protein kinase C-deltadependent control of fibroblast collagen synthesis in pulmonary fibrosis. J Biol Chem 2004, 279:28315-28319

62. Bogatkevich GS, Gustilo E, Oates JC, Feghali-Bostwick C, Harley RA, Silver RM, Ludwicka-Bradley A: Distinct PKC isoforms 
mediate cell survival and DNA synthesis in thrombin-induced myofibroblasts. Am J Physiol Lung Cell Mol Physiol 2005, 288:L190-L201

63. Luzina IG, Highsmith K, Pochetuhen K, Nacu N, Rao JN, Atamas SP: PKCalpha mediates CCL18-stimulated collagen production in pulmonary fibroblasts. Am J Respir Cell Mol Biol 2006, 35:298-305

64. Moiseeva EP, Leyland ML, Bradding P: CADM1 isoforms differentially regulate human mast cell survival and homotypic adhesion. Cell Mol Life Sci 2012, 69:2751-2764
65. Hollins F, Kaur D, Yang W, Cruse G, Saunders R, Sutcliffe A, Berger P, Ito A, Brightling CE, Bradding P: Human airway smooth muscle promotes human lung mast cell survival, proliferation, and constitutive activation: cooperative roles for CADM1, stem cell factor, and IL-6. J Immunol 2008, 181:2772-2780

66. Padawer J: Mast cells: extended lifespan and lack of granule turnover under normal in vivo conditions. Exp Mol Pathol 1974, 20: $269-280$ 